\title{
Applications of elastin-like polypeptides in drug delivery
}

\author{
Sarah R MacEwan ${ }^{a, b}$ and Ashutosh Chilkotia,b, ${ }^{*}$ \\ aDepartment of Biomedical Engineering, Duke University, Durham, NC, 27708, USA

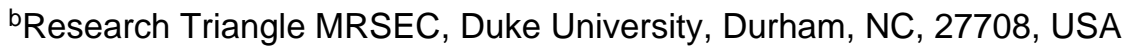

\begin{abstract}
Elastin-like polypeptides (ELPs) are biopolymers inspired by human elastin. Their lower critical solution temperature phase transition behavior and biocompatibility make them useful materials for stimulus-responsive applications in biological environments. Due to their genetically encoded design and recombinant synthesis, the sequence and size of ELPs can be exactly defined. These design parameters control the structure and function of the ELP with a precision that is unmatched by synthetic polymers. Due to these attributes, ELPs have been used extensively for drug delivery in a variety of different embodiments - as soluble macromolecular carriers, self-assembled nanoparticles, cross-linked microparticles, or thermally coacervated depots. These ELP systems have been used to deliver biologic therapeutics, radionuclides, and small molecule drugs to a variety of anatomical sites for the treatment of diseases including cancer, type 2 diabetes, osteoarthritis, and neuroinflammation.
\end{abstract}

\section{Keywords}

elastin-like polypeptides; lower critical solution temperature; phase separation; self-assembly; drug delivery

\section{Introduction}

Stimulus-responsive biomaterials are a promising resource with applications in controlled drug delivery. Elastin-like polypeptides (ELPs) are one such biomaterial whose composition is inspired by the repetitive hydrophobic domains of human tropoelastin [1]. ELPs are biopolymers composed of short repeating peptide motifs, of which the most common is the pentapeptide VPGXG where $\mathrm{X}$ is a guest residue that is any amino acid except proline. ELPs exhibit stimulus-responsive lower critical solution temperature (LCST) phase transition behavior. They are soluble at temperatures below a characteristic cloud point temperature $\left(T_{t}\right)$ (also known as the inverse transition temperature) and aggregate into micron scale coacervates above the $T_{t}[2]$. This phase transition occurs over a short time

\footnotetext{
(C) 2014 Elsevier B.V. All rights reserved.

*To whom correspondence should be addressed. chilkoti@duke.edu.
}

Publisher's Disclaimer: This is a PDF file of an unedited manuscript that has been accepted for publication. As a service to our customers we are providing this early version of the manuscript. The manuscript will undergo copyediting, typesetting, and review of the resulting proof before it is published in its final citable form. Please note that during the production process errors may be discovered which could affect the content, and all legal disclaimers that apply to the journal pertain. 
scale and is typically reversible, such that ELP coacervates will resolubilize when returned to a temperature below the $T_{t}$.

ELPs are useful materials in a variety of applications since their stimulus-response is highly tunable [3]. The $T_{t}$ is precisely controlled by intrinsic parameters including the composition and molecular weight (MW) of the ELP (Figure 1) and is also influenced by extrinsic factors such as concentration, solutes, and, for some ELP sequences, by solution $\mathrm{pH}$. The hydrophobicity of the guest residue is a primary intrinsic parameter that controls the $T_{t}$, as hydrophobic guest residues depress the $T_{t}$, while hydrophilic guest residues elevate the $T_{t}[2$, $4,5]$. The MW of the ELP is inversely related to the $T_{t}$, such that an increase in MW leads to a decrease in the $T_{t}[6]$. The concentration of an ELP solution also influences the $T_{t}$ in an inverse relationship, such that an increase in ELP concentration results in a lower $T_{t}[6]$. The ELP $\mathrm{T}_{\mathrm{t}}$ is additionally influenced by cosolutes, such as salts. Most notably, kosmotropic salts $\left(\mathrm{Cl}^{-}\right.$and higher on the Hofmeister scale of anions) depress the ELP $\mathrm{T}_{t}$, with increasing concentration of salt enhancing this effect [7]. Furthermore, the local $\mathrm{pH}$ can influence the $T_{t}$ of ELP sequences that include ionizable guest residues $[8,9]$.

ELPs are typically produced recombinantly from synthetic genes, whose construction requires specialized methods for assembling repeating genes with precise control over gene length. Concatemerization is the oldest technique to create a library of repetitive ELP genes with varying lengths. In concatemerization, genes with cohesive ends self-ligate to create oligomers within a receiving cloning vector. Although this provides a rapid method to assemble ELP genes of varying length, the genes created by concatemerization have a distribution of lengths, which does not ensure that a desired gene length will be achieved. Concatemerization is therefore less desirable when an exact MW of an ELP, and thus an exact ELP gene length, is required. Furthermore, successful insertion of concatemerization products into the cloning vector is biased to a low degree of polymerization (typically $\leq 30$ pentapeptides), such that this technique is less useful for applications where a higher degree of polymerization is required.

Concatemerization is useful, however, when paired with other assembly methods to quickly build ELP genes with a precise length. Recursive directional ligation (RDL) is one such method that involves the step-wise oligomerization of short ELP genes derived from concatemerization [10]. Recursive gene addition builds the length of the encoded ELP in an existing vector by using a single cut site for the insertion of an ELP gene with complementary sticky ends. However, RDL runs the risk of self-ligation of both the receiving plasmid and the ELP gene insert, which decreases the efficiency of this method.

Recursive directional ligation by plasmid reconstruction (PRe-RDL) solves the problem of self-ligation by introducing restriction sites that deconstruct two parent plasmids containing ELP genes, such that reconstruction of a functional plasmid is only achieved by successful ligation of the two plasmid fragments containing the ELP-encoding components [11]. Due to the step-wise nature of both RDL and PRe-RDL, these methods can be used to create ELPs with complex architecture at their sequence level, such as multi-block copolymers. These techniques also allow insertion of peptide or protein sequences at the $\mathrm{N}$ - and $\mathrm{C}$-terminals of an ELP gene, providing chemical or biological activity for drug delivery applications. 
However, these techniques require multiple cloning steps to create an ELP gene with a high degree of polymerization.

Rapid synthesis of ELP genes with a high degree of polymerization can be achieved in one step with overlap extension rolling circle amplification (OERCA) [12]. This assembly method uses a circular ssDNA that encodes a desired repeat unit of the ELP gene. Rolling circle amplification (RCA) is first carried out to create a linear ssDNA containing several copies of the circular template. RCA is followed by polymerase chain reaction (PCR) with primers that are complementary to the ends of the product from the RCA reaction, resulting in dsDNA and further lengthening of the genes by overlap extension. OERCA is a powerful method for multiplexed synthesis of repetitive genes, whose size range is tunable and is typically longer than that achieved with concatemerization. We note, however, that OERCA is limited to the synthesis of homopolymer ELPs and thus cannot be used to create genes that encode alternative architectures, such as block copolymers.

ELP genes are typically expressed in E. coli, although ELPs have also been expressed in yeast [13-15], fungus [16], and plants [17-19]. Purification of ELPs from E. coli lysate is achieved by exploiting the ELP's thermal responsiveness using a non-chromatographic separation method called inverse transition cycling (ITC) [20]. ITC has four sequential steps: (1) selective aggregation of the ELP by raising the solution temperature above the $T_{t}$ or by depressing the $T_{t}$ below the solution temperature with the addition of kosmotropic salts; (2) centrifugation above the $T_{t}$ to pellet the aggregated ELP and discard soluble contaminates in the supernatant; (3) recovery of soluble ELP with dissolution of the pelleted material by reversing its phase transition in a buffer at a temperature below the $\mathrm{T}_{\mathrm{t}}$; and (4) centrifugation below the $T_{t}$ to pellet insoluble contaminants and collect purified soluble ELP in the supernatant. Repeating cycles of centrifugation above and below the $T_{t}$ increases the purity of the ELP product. ITC is a powerful alternative to chromatography that allows easy purification of ELPs with equipment found in most biology laboratories.

As biologically inspired recombinant materials, ELPs have distinct properties that make them useful for applications in drug delivery. ELPs are biocompatible and are therefore suitable for local and systemic administration, as they induce minimal inflammatory and immune effects in animal models [21-23] and can be administered to humans without eliciting an adverse immune response [24]. Additionally, the genetically encoded design of ELPs permits exact control over the sequence of the ELP, which can be exploited to precisely specify the location at which a biological drug — peptide or protein-is fused to an ELP, or the location at which a reactive residue is placed for covalent conjugation of the ELP with small molecule drugs. Furthermore, their genetically encoded design leads to perfectly monodisperse polymers. As MW influences important biological parameters, like circulation clearance, this monodispersity allows improved prediction of the ELP behavior in vivo, as compared to alternative polydisperse materials.

The biological composition of ELPs also ensures their biodegradation, permitting their safe break down into peptides and amino acids that can be easily cleared from the body. The kinetics of ELP degradation have been analyzed both in vitro and in vivo with ${ }^{14} \mathrm{C}$-labeled ELPs, where the degradation products were visualized by SDS-PAGE and quantified by 
radioactivity [25]. A degradation rate of approximately $2.5 \mathrm{wt} \% /$ day was observed following intravenous administration of a $59.4 \mathrm{kDa}{ }^{14} \mathrm{C}$-labeled ELP [26]. This degradation rate suggests that ELPs can strike a good balance between in vivo stability, over the time course required for many drug delivery applications, and clearance over several weeks. Although all ELPs are susceptible to eventual clearance by mechanisms of degradation, it is important to consider the effect of ELP aggregation on degradation kinetics for ELPs that are used in vivo in their aggregated coacervate phase. Ex vivo experiments have shown that soluble ELPs below their $T_{t}$ were enzymatically degraded by both elastase and collagenase.

However, a decrease in enzymatic degradation by collagenase was observed at temperatures above the $T_{t}$ of a homopolymer ELP, in which the ELP was aggregated into micron-scale coacervates, or at temperatures above the critical micelle temperature of diblock copolymer ELPs, at which the hydrophobic ELP domain was sequestered in the micelle core [27]. This differed from degradation by elastase, which was efficient regardless of ELP aggregation. These experiments demonstrated that aggregation can be a factor in the degradation rate of ELPs and their higher order assemblies, and that these effects are protease specific.

\section{Architectures and assemblies of ELP drug carriers}

\subsection{Soluble ELP unimers}

Due to their recombinant design and stimulus-response, ELPs can serve as useful carriers for drug delivery in a variety of sequences, architectures, and higher order assemblies (Table 1). ELPs in their soluble state-which we term unimers to distinguish them from their selfassembled or aggregated counterparts - are useful materials for enhancing the size and stability of appended cargo and conferring stimulus-responsive behavior to these conjugates. These ELPs are typically designed as homopolymers (wherein the guest residue is a single amino acid) or as pseudorandom ELPs (wherein the guest residue is a mixture of residues) that are chosen to impart a $T_{t}$ above body temperature so that they are soluble in vivo. These features, in combination with the ease of ELP purification by ITC and their genetically encoded design, make ELPs excellent purification tags for fusion partners such as recombinant peptide and protein drugs [28]. ITC can be used for the purification of these genetic fusions because the ELP retains its LCST behavior in the fusion, although the $T_{t}$ of the ELP fusion may vary from the $T_{t}$ of the ELP alone [29]. The simplicity and low cost of ITC purification provides advantages over alternative methods for recombinant protein purification, such as chromatography. After purification, the ELP tag can be retained as a macromolecular drug carrier or alternatively, if free recombinant peptide or protein is desired, the ELP tag can be cleaved and removed from its peptide or protein partner.

A recombinant fusion partner can be released from the ELP tag by inclusion of an intervening cleavable peptide linker. Peptide linkers cleaved by enzymes (e.g., thrombin [20, 30], enterokinase [31], human rhinovirus 3C [32], or small ubiquitin-related modifier [32, 33]), and chemical reagents (e.g., hydroxylamine [34]), as well as self-cleaving inteins [3537] have been exploited for release of ELPs from recombinant peptides and proteins. The application of ELPs for the synthesis and purification of recombinant therapeutics has been demonstrated by the production of antimicrobial peptides in E. coli. Antimicrobial peptides have been fused to large ELP unimers and exhibited poor activity, which allowed their 
overexpression in their bacterial host without toxicity. However, following their release from the ELP purification tag, these peptides regained their antimicrobial function. Antimicrobial peptides such as cecropin AD [31], halocidin18 [34], moricin CM4 [37], and human $\beta$-defensin 4 [37] have been purified as ELP fusions, cleaved from their ELP tag, and shown to exhibit antimicrobial activity against a spectrum of bacterial targets such as E. coli, S. aureus, M. luteus, and P. aeruginosa.

An alternative means of cleaving recombinant proteins from ELP purification tags has recently been developed using the transpeptidase Sortase A (SrtA). Protein ELP fusions with an intervening SrtA recognition site (an LPETG peptide) can undergo site-specific cleavage from the ELP that is accompanied with the addition of a short nucleophilic triglycine peptide. Use of a SrtA ELP fusion as the cleavage enzyme provides additional convenience to this method as it allows removal of the cleaved ELP tag and SrtA ELP fusion in one final round of ITC. Dialysis is necessary, however, to recover pure recombinant protein by removing the excess triglycine that is added to trigger the cleavage reaction. This technique was first used to produce recombinant tumor necrosis factor a (TNFa), an apoptosisinducing cytokine, which exhibited equivalent activity to commercially available TNFa in an in vitro fibrosarcoma cytotoxicity assay [38]. Due to the inherent addition of the nucleophilic triglycine peptide following SrtA-mediated liberation of the recombinant protein from the ELP tag, this method also provides the option to site-specifically functionalize the recombinant protein at its $\mathrm{C}$-terminus. This approach has been used to functionalize tumor necrosis factor-related apoptosis-inducing ligand (TRAIL) with the small molecule chemotherapeutic camptothecin (CPT). The SrtA-catalyzed reaction of a TRAIL ELP fusion with a CPT-functionalized triglycine created a TRAIL-CPT conjugate that exhibited in vitro cytotoxicity in adenocarcinoma breast cancer cells that was comparable to a physical mixture of TRAIL and CPT.

After purification, the ELP tag can alternatively be retained on the peptide or protein ELP fusion if a macromolecular carrier is useful for the delivery of the appended biologic drug. ELP fusions have been investigated with a variety of biologic therapeutics, including cytokines IL-1ra [39], IL-4 [40], IL-10 [19, 40], and erythropoietin (EPO) [17] as well as antibodies, including anti-TNF single-domain antibody $\left(\mathrm{TNF}_{\mathrm{H}} \mathrm{V}_{\mathrm{H}} \mathrm{H}\right)$ [18] and anti-human immunodeficiency virus neutralizing antibody (HIV-nAb) fragments [41]. A unimer ELP carrier can provide advantages in drug delivery by improving the pharmacokinetics and biodistribution of its drug cargo, as compared to the behavior of free drug alone. For example, an intravenously administered $\mathrm{TNFV}_{\mathrm{H}} \mathrm{H}$ ELP fusion exhibited a 24-fold increase in serum half-life compared to TNF- $\mathrm{V}_{\mathrm{H}} \mathrm{H}$ alone (Figure 2), likely due to the enhanced MW of the fusion leading to decreased renal clearance as compared to $\mathrm{TNF}_{\mathrm{H}} \mathrm{V}_{\mathrm{H}} \mathrm{H}$ [18]. In vivo activity of this TNF- $\mathrm{V}_{\mathrm{H}} \mathrm{H}$ ELP fusion was confirmed with the inhibition of proinflammatory TNF activity, as measured by animal survival, equivalent to TNF- $\mathrm{V}_{\mathrm{H}} \mathrm{H}$ alone in a mouse model of induced septic shock.

Depending on the peptide or protein fusion, the ELP tag may influence the activity of the therapeutic moiety. EPO fusions, for example, with ELP tags from 5-240 pentapeptides in length did not exhibit a change in binding to human EPO receptor, as compared to recombinant human EPO alone, demonstrating that ELP fusions can remain biologically 
active [17]. For other fusions, however, the ELP tag can result in decreased therapeutic efficacy. An IL-10 fusion with ELP demonstrated cytokine function, but 80-times higher levels of IL-10 ELP fusions were required to induce cytokine activity equivalent to commercially available recombinant IL-10 [19]. IL-10 acts as a homodimer and although dimerization was not believed to be affected by the ELP fusion $[19,40]$, it was likely that the ELP either changed the folding and conformation of IL-10 or sterically hindered binding to its receptor, resulting in decreased activity.

Recombinant functionalization of ELP unimers can alternatively be used as a tool to improve drug delivery as fusion with targeting or internalization peptides can enhance the accumulation or intracellular delivery of drug carriers at the disease site. Cell-specific affinity targeting has been demonstrated by ELPs functionalized with peptide ligands that recognize receptors upregulated in diseased tissues. For example, an ELP unimer with a tumor-homing AP1 peptide embedded in the ELP sequence was shown to preferentially accumulate in tumors that overexpressed the AP1 target, the interleukin 4 receptor [42]. Alternatively, enhanced cellular uptake by non-specific, receptor-independent mechanisms has been achieved by functionalization of ELPs with cell-penetrating peptides (CPPs), such as peptide fragments from the Drosophila Antennapaedia transcription factor (penetratin), HIV trans-activator of transcription (TAT), and Kaposi fibroblast growth factor signal peptide (MTS) [43]. The increased intracellular delivery of CPP-functionalized ELP could enhance the interaction of drug cargo with intracellular therapeutic targets and thereby increase drug efficacy. This was first demonstrated with kinase inhibitor peptide p21 drug cargo, which induced enhanced cancer cell death when delivered by penetratinfunctionalized ELP, as compared to a non-functionalized ELP control [43].

As an alternative to the gene-level fusion with peptide and protein therapeutics, the recombinant design of ELPs also allows the site-specific incorporation of reactive residues that can be used for covalent conjugation of small molecule drugs. Lysine [44] and cysteine $[45,46]$ residues, for example, have been used as unique reactive sites in an ELP sequence for the conjugation of the small molecule chemotherapeutic doxorubicin. In these systems, release of free drug is enabled by the incorporation of a cleavable linker between the ELP and the drug molecule, such as an acid-labile hydrazone bond [44, 45] or a cathepsin enzyme-cleavable GFLG peptide linker [46]. These linkers release the free drug intracellularly after endocytic uptake and accumulation in the acidic, enzyme-rich environment of endosomes and lysosomes. These ELPdrug conjugates thus serve as macromolecular carriers for small molecule drugs, while also providing release of active drug inside the cell.

\subsection{Diblock copolymer ELP assemblies}

Precise control over the ELP sequence can be used to create sequence architecture that encodes ELP self-assembly. This has been extensively demonstrated with ELP diblock copolymers (ELP $\mathrm{BC}_{\mathrm{BC}} \mathrm{s}$ ), consisting of a hydrophobic ELP segment fused to a hydrophilic ELP segment. The guest residues and lengths of the two segments are designed such that below a critical temperature the ELP $\mathrm{BC}_{\mathrm{BC}}$ is well solvated and thereby exists as a soluble unimer. However, when the temperature is raised above a critical temperature the selective 
dehydration of the hydrophobic ELP segment increases the amphiphilicity of the ELP $\mathrm{BC}_{\mathrm{BC}}$, which drives self-assembly of the $\mathrm{ELP}_{\mathrm{BC}}$ into micelles. The hydrophobic ELP segment stabilizes the micelle core while the hydrophilic ELP segment remains solvated and forms the micelle corona. A further increase intemperature causes the hydrophilic segment to also dehydrate, which results in aggregation of the micelles into micron-scale particles. This selfassembly behavior was first demonstrated with an ELP $_{\mathrm{BC}}$ composed of a hydrophilic [VPGEG(IPGAG) $\left.)_{4}\right]_{14}$ block and hydrophobic [VPGFG(IPGVG) $\left.)_{4}\right]_{16}$ block connected via a VPGEG linker [60]. The stark difference in hydrophobicity between hydrophilic guest residues glutamic acid and alanine versus hydrophobic guest residues phenylalanine and valine led to self-assembly into spherical and cylindrical nanoparticles at a temperature above the $\mathrm{T}_{\mathrm{t}}$ attributed to the hydrophobic block $\left(<25^{\circ} \mathrm{C}\right)$.

Design parameters that control self-assembly have been systematically explored with ELP $_{\mathrm{BC}}$ s composed of a hydrophilic $(\mathrm{VPGXG})_{\mathrm{n}}\left[\mathrm{X}=\mathrm{V}_{1} \mathrm{~A}_{8} \mathrm{G}_{7} ; \mathrm{n}=64,96\right.$, or 128] domain and hydrophobic (VPGVG) $)_{\mathrm{m}}[\mathrm{m}=60,90$, or 120] domain [47]. Dynamic light scattering, static light scattering, and cryogenic transmission electron microscopy analysis confirmed that $\operatorname{ELP}_{\mathrm{BC}}$ s with block ratios (n:m) between 1:2 and 2:1 self-assembled into monodisperse spherical micelles above their critical micellization temperature (CMT), defined as the temperature at which the unimer-to-micelle transition occurs. ELP $_{\mathrm{BC}}$ unimers were approximately 5-10 $\mathrm{nm}$ in hydrodynamic radius $\left(\mathrm{R}_{\mathrm{h}}\right)$, while the temperature-triggered selfassembled micelles had an $R_{h}$ of $30-40 \mathrm{~nm}$. The overall length of the ELP $P_{B C}$ as well as the hydrophilic-to-hydrophobic block ratio influenced the size of the self-assembled micelles, whereas the $T_{t}$ of the hydrophobic ELP segment controlled the CMT. Further elucidation of the effects of design parameters on ELP $_{\mathrm{BC}}$ self-assembly have recently been achieved with mathematical modeling of the $\mathrm{ELP}_{\mathrm{BC}}$ phase transitions, such that the CMT and micelle aggregation transition of the $\mathrm{ELP}_{\mathrm{BC}}$ could be predicted by the thermal behaviors of the individual ELP blocks from which the ELP $_{\mathrm{BC}}$ was constructed [61].

Due to the complex environment that self-assembled $\operatorname{ELP}_{\mathrm{BC}} \mathrm{S}$ will encounter in vivo, efforts have been made to enhance the stability of self-assembled $\mathrm{ELP}_{\mathrm{BC}} \mathrm{S}$ in the presence of proteins, such as albumin. To improve the stability of ELP $_{\mathrm{BC}}$ assemblies, a hydrophilic VPGEG[(VPGVG)(VPGEG)(VPGVG)(VPGEG)(VPGVG) $]_{10}$ block and hydrophobic $\left[(\mathrm{IPGVG})_{2}(\mathrm{VPGYG})(\mathrm{IPGVG})_{2}\right]_{12}$ or ${ }_{15} \mathrm{VPGYG}$ block were joined via a cysteine-rich $\mathrm{C}_{4} \mathrm{G}_{3}$ linker [62]. The local cysteine concentration at the boundary between hydrophobic and hydrophilic ELP domains was proposed to increase stability of the self-assembled micelles by formation of thiol cross-links between $\mathrm{ELP}_{\mathrm{BC}} \mathrm{s}$ within the assembly. Indeed, greater than $90 \%$ of cysteines were believed to participate in disulfide bonds, with less than $10 \%$ of cysteines existing in their reduced state. This self-assembled ELP $_{\mathrm{BC}}$ was able to resist a significant change in nanoparticle size in the presence of $3 \mathrm{mg} / \mathrm{mL}$ bovine serum albumin (BSA), whereas breakage of cysteine interactions with the reducing agent tris(2carboxyethyl)phosphine led to a 6-fold increase of the nanoparticle $R_{h}$ in the presence of BSA. Local cross-linking within the micelle may thus improve stability in biological environments like blood plasma, in which albumin is the most abundant protein.

The organized assembly of $\mathrm{ELP}_{\mathrm{BC}}$ micelles can be exploited for multivalent presentation of biologically active motifs on the micelle corona. Due to their genetically encoded design, 
$\mathrm{ELP}_{\mathrm{BC}} \mathrm{S}$ are particularly suited for functionalization with peptide motifs. For example, RGD and NGR peptides, which are ligands for receptors overexpressed on tumor vasculature, have been genetically fused at the hydrophilic terminus of an ELP $_{\mathrm{BC}}$ [47]. Appending these peptides to the hydrophilic terminus of the $\mathrm{ELP}_{\mathrm{BC}}$ did not perturb micelle formation, and thus upon temperature-triggered assembly the peptides were multivalently presented on the micelle corona. This multivalent presentation led to greater internalization of NGRfunctionalized $\mathrm{ELP}_{\mathrm{BC}}$ micelles, as compared to non-functionalized $\mathrm{ELP}_{\mathrm{BC}}$ micelles, in HT-1080 cells expressing the NGR receptor, aminopeptidase N (CD13). In vivo, NGRdecorated ELP $_{\mathrm{BC}}$ micelles showed increased interaction with vasculature in tumors that overexpressed CD13 and exhibited greater accumulation in the extravascular space of the tumor, compared to normal tissue, as observed by intravital confocal microscopy in murine dorsal fold window chamber tumors [48]. Furthermore, the internalization of NGRfunctionalized $\mathrm{ELP}_{\mathrm{BC}}$ micelles could be controlled in vitro by manipulation of the NGR multivalency with $\mathrm{ELP}_{\mathrm{BC}}$ self-assembly, such that cellular uptake was higher for NGRELP $_{\mathrm{BC}}$ micelles above their CMT, as compared to soluble NGR-ELP $\mathrm{BC}_{\mathrm{BC}}$ unimers below their CMT [47]. These results support the role of multivalency in targeted receptor-mediated uptake and provide a mechanism of controlling cell uptake by manipulating multivalency with self-assembly of $\mathrm{ELP}_{\mathrm{BC}}$ micelles. When the $\mathrm{ELP}_{\mathrm{BC}} \mathrm{CMT}$ is carefully tuned to clinically relevant thermal conditions, then self-assembly can be controlled in vivo by extrinsic triggers, such as mild hyperthermia. Applications of $\mathrm{ELP}_{\mathrm{BC}} \mathrm{S}$ using hyperthermiatriggered self-assembly are discussed in Section 3.2.

$\mathrm{ELP}_{\mathrm{BC}} \mathrm{S}$ can also support multivalent presentation of proteins for purposes of targeted cellular uptake. The knob domain of adenovirus serotype 5 fiber protein (knob) binds the coxsackievirus and adenovirus receptor (CAR), which is expressed in various tissues through the body, including the liver. The knob domain was genetically appended to the hydrophilic terminus of an $\mathrm{ELP}_{\mathrm{BC}}$ and, despite the size of the protein $(>10 \mathrm{kDa})$, did not perturb $\mathrm{ELP}_{\mathrm{BC}}$ micelle assembly [49]. The knob-functionalized $\mathrm{ELP}_{\mathrm{BC}}$ s formed nanoparticles approximately $40 \mathrm{~nm}$ in diameter at $37^{\circ} \mathrm{C}$, which achieved greater internalization in hepatocytes that overexpressed CAR, as compared to non-functionalized $E P_{B C}$ micelles (Figure 3). Protein functionalization can therefore also serve as a means to increase the intracellular delivery of $\mathrm{ELP}_{\mathrm{BC}} \mathrm{s}$ by targeting upregulated cell surface receptors.

Protein functionalization of $\mathrm{ELP}_{\mathrm{BC}} \mathrm{s}$ can furthermore be exploited for drug loading and retention when the appended protein specifically binds to a therapeutic cargo. This was demonstrated by $\mathrm{ELP}_{\mathrm{BC}} \mathrm{S}$ functionalized with FK506 binding protein 12 (FKBP), which is the binding partner of the small molecule drug rapamycin. ELP $_{\mathrm{BC}}$ nanoparticles that both encapsulated rapamycin in the hydrophobic nanoparticle core and bound rapamycin on the FKBP-functionalized nanoparticle corona exhibited biphasic drug release, with fast $(1.9 \mathrm{~h}$ half-life) and slow (57.8 h half-life) drug release phases attributed to the release of encapsulated and corona-bound drug, respectively [50]. Due to rapamycin's immunosuppressant and antiproliferative properties, this drug loading method of proteinfunctionalized $\mathrm{ELP}_{\mathrm{BC}}$ s demonstrated efficacy in vivo both by suppressing autoimmune effects in murine Sjogren's syndrome [51] and regressing tumor growth of breast cancer xenografts in mice [50], while limiting toxicity as compared to free drug. 


\subsection{Conjugation-driven ELP assemblies}

Self-assembly of soluble ELP unimers can also be induced by asymmetric attachment of hydrophobic moieties to one end of the ELP. This phenomenon was first observed with a pseudorandom hydrophilic ELP unimer conjugated with multiple copies of the hydrophobic small molecule chemotherapeutic doxorubicin [52]. The hydrophilic ELP included a short conjugation domain $(\mathrm{GGC})_{8}$ at the $\mathrm{C}$-terminus, which provided eight unique reactive sites for covalent drug attachment through an acid-labile hydrazone linker with a terminal maleimide. The attachment of approximately five drug molecules per ELP imparted sufficient local hydrophobicity at the ELP's C-terminus to induce self-assembly, leading to sequestration of the hydrophobic drug in the core of spherical nanoparticles approximately $40 \mathrm{~nm}$ in diameter, while the hydrophilic ELP formed the solvated nanoparticle corona. These doxorubicin-loaded nanoparticles exhibited prolonged circulation half-life, increased tumor accumulation, decreased off-target accumulation, and enhanced survival time in mice bearing C26 tumors, as compared to free drug, demonstrating the advantages of nanoparticle carriers for delivery of small molecule drugs.

This conjugation-driven self-assembly is not unique to doxorubicin, but is rather a general phenomenon based on the hydrophobicity of the covalently attached cargo. The rules for conjugation-driven self-assembly were explored by the attachment of 14 different small molecules displaying a range of hydrophobicity as quantified by their $\operatorname{LogD}$ octanol-water distribution coefficient from -1.0 (hydrophilic) to 4.0 (hydrophobic) [53]. Each small molecule contained a maleimide group for covalent attachment to the cysteine-rich conjugation domain on the ELP's C-terminus. Attachment of small molecules with a $\log D$ less than 1.5 did not trigger self-assembly, while attachment of small molecules with $\log D$ greater than 1.5 induced self-assembly of particles with diameters between 60 and $120 \mathrm{~nm}$. This threshold in hydrophobicity required to drive self-assembly was confirmed by the conjugation of drug molecules, where attachment of chemotherapeutic gemcitabine $(\log D$ of -2.2) and analgesic oxycodone ( $\log D$ of 1.2) did not induce self-assembly, while the attachment of chemotherapeutic paclitaxel ( $\log D$ of 4.0) did result in self-assembly of nanoparticles approximately $110 \mathrm{~nm}$ in diameter. Conjugation-driven self-assembly of ELP unimers can thus be predicted by the hydrophobicity of the drug cargo, which facilitates the design of new drug-loaded ELP nanoparticles.

This approach, however, depends on a reproducible level of drug conjugation to ensure adequate hydrophobicity at the chain terminus to drive self-assembly, which is not always well controlled for covalent conjugation. New approaches are currently being explored in our laboratory to genetically encode hydrophobic moieties at the chain end. This alternative approach will provide a mechanism of self-assembly that is independent of drug loading and drug hydrophobicity, which will also circumvent the batch-to-batch variability that is inherent in covalent conjugation.

\subsection{ELP polyplexes}

ELP assembly can also be induced by charge effects, such that ionic interactions between an ELP and drug cargo can produce nanoparticles. This is exemplified by ELP polyplexes for the delivery of gene therapies, wherein a positively charged ELP can condense negatively 
charged DNA into nanoparticles that enable the intracellular delivery of therapeutic genes.

Although positively charged ELPs have been created by inclusion of cationic guest residues $[63,64]$, this low charge density was not ideal for DNA condensation as compared to the high charge density provided by contiguous cationic residues. ELPs for DNA condensation have thus been specifically designed as a genetic fusion of an ELP and a cationic domain consisting of an eight-residue oligolysine peptide [54]. This cationic ELP successfully condensed plasmid DNA into particles approximately $32-115 \mathrm{~nm}$ in radius, depending on the N/P ratio (the ratio of cationic amine groups contributed by the ELP to anionic phosphate groups contributed by the DNA). Furthermore, when loaded with green fluorescent protein (GFP)-encoding plasmid this ELP polyplex successfully induced expression of GFP following transfection of MCF-7 breast cancer cells. Although the transfection efficiency of ELP polyplexes was less than that achieved by a positive control polyethylenimine (PEI) vehicle, the greatly decreased toxicity of the ELP carrier, as compared to PEI, demonstrated the potential advantage of ELP-based polyplexes for the delivery of gene therapies over alternative carriers with toxic side-effects.

\subsection{Coacervate ELP nanoparticles}

ELP assembly can alternatively be induced by an external stimulus when the temperaturetriggered ELP aggregation results in the spontaneous coacervation of ELPs into nanoscale particles. This has been demonstrated by an ELP variant composed of the repeating pentapeptide VPAVG, which aggregates into polydisperse nanoparticles when raised above its $\mathrm{T}_{\mathrm{t}}$ of approximately $30^{\circ} \mathrm{C}$. This ELP exhibits significant hysteresis, such that its transition is not reversible at its $T_{t}$ upon cooling and disassembly of these coacervates does not occur until the temperature is depressed approximately $15^{\circ} \mathrm{C}$ lower than the $T_{t}$ [65]. These unique properties were explored for the encapsulation of drug cargo and prolonged drug release for the promotion of bone growth. Bone morphogenetic protein (BMP) -2 and -14 were mixed with ELP and heated to $37^{\circ} \mathrm{C}$ to create drug loaded nanoparticles approximately 190-295 $\mathrm{nm}$ in diameter [55]. An initial burst of drug release followed by sustained release over 14 days allowed these BMP-loaded ELP nanoparticles to promote bone formation in vitro by increasing alkaline phosphatase activity and mineralization in $\mathrm{C} 2 \mathrm{C} 12$ myoblast cells.

In alternative applications, the ELP coacervate can serve as both the carrier and a therapeutic component of the nanoparticle drug vehicle. In wound healing applications, the inherent bioactivity of the elastogenic [VG-(VPGVG) $\left.)_{4}-\mathrm{VPG}\right]_{8}$-[VG-(VPGVG) $)_{2}$-VPGCGVPGVG$V P G]_{2}$ ELP motif was used in combination with keratinocyte growth factor (KGF) by genetic fusion of these two components [56]. The ELP provided bioactivity and selfassembly, as the temperature-triggered aggregation of the KGF ELP fusion at $37^{\circ} \mathrm{C}$ created nanoparticle coacervates approximately $200 \mathrm{~nm}$ in diameter. KGF ELP nanoparticles increased reepithelialization of wounds in a diabetic mouse model, as compared to either component alone, and resulted in optimal granulation of the wound, as compared to excessive granulation induced by a physical mixture of the components, supporting the advantage of dual delivery of this therapeutic fusion in a nanoparticle carrier. Although the mechanism by which the KGF ELP fusion outperformed a physical mixture of the two components was not elucidated, it is plausible that the coacervated nanoparticles may serve 
as a local depot for sustained release of both biologically active components, which could favorably impact re-epithelialization and tissue granulation.

\subsection{Cross-linked ELP particles}

Cross-linking of ELPs provides a mechanism for assembly in which ELP structures can be stabilized while retaining their thermal properties. Cross-linking of ELPs has been achieved with a variety of approaches including photoirradiation [66], chemical cross-linking [67], and enzyme-catalyzed cross-linking [68]. These strategies differ in their specificity of crosslinking and create materials with variable properties such as mechanical strength and drug release kinetics [67]. Furthermore, these crosslinking processes differ in their biocompatibility, which precludes the use of some of these strategies for in vivo crosslinking. Key cross-linking parameters, such as cross-link length and density, can be controlled by the ELP design, as reactive residues for cross-linking can either be placed periodically along the ELP [64] or clustered within cross-linking domains that are segregated within the ELP [69].

As an alternative to physical interactions leading to particle formation by temperaturetriggered ELP coacervation, covalent interactions can also be used to create stable microparticles via cross-linking. Mixtures of albumin and ELPs that contain lysine as a fraction of their guest residues formed microspheres (> $200 \mu \mathrm{m}$ in diameter) in a water-in-oil emulsion, and were stabilized by glutaraldehyde cross-linking [57]. In their cross-linked state, the ELP microspheres retained their thermal response, exhibiting a $\mathrm{T}_{\mathrm{t}}$ of approximately $39^{\circ} \mathrm{C}$ that could be exploited for temperature-triggered drug release. Upon heating above the $T_{t}$, the ELP microspheres decreased in volume and increased in porosity due to the cross-link-constrained ELP aggregation (Figure 4). Model drugs, including albumin and prednisone acetate, were loaded into the microspheres by coincubation first above and then below the ELP $\mathrm{T}_{\mathrm{t}}$. Subsequent drug release was achieved first by a burst release from the microsphere surface, followed by a sustained release that could be accelerated by an increase in temperature above the $T_{t}$, leading to expulsion of drug by the decrease in particle volume and increase in particle porosity. Covalent cross-linking of ELPs can thus provide stable assemblies while retaining stimuli-responsive behavior for temperature-triggered drug release.

An alternative two-step cross-linking procedure was used to form microparticles by waterin-oil emulsion of ELP albumin mixtures, from which a core-shell microcapsule was created by temporary $\rho$-phthalaldehyde cross-linking followed by stable glutaraldehyde crosslinking of the microcapsule shell [58]. This architecture behaved similarly to the solid microparticles, where an increase in temperature above the ELP $\mathrm{T}_{\mathrm{t}}$ led to a decrease in volume and an increase in porosity. The thermal responsiveness of the core-shell microparticles allowed loading and temperature-dependent release of model drugs including rhodamine B, FITC, and rhodamine-labeled BSA.

Hollow ELP spheres have also been synthesized by templating techniques, where ELPs were adsorbed on a negatively charged sulfonated polystyrene beads by aggregation and ionic interactions, then enzymatically cross-linked by transglutaminase via reactive lysine and glutamine residues, after which the polystyrene supports were dissolved with 
tetrahydrofuran [59]. Varying the polystyrene template size resulted in 100-1000 nm diameter hollow spheres that were exploited for gene delivery by the addition of polyplexes composed of GFP-encoding plasmid DNA and block copolymers of poly(2-dimethylaminoethyl-methacrylate) (PDMAEMA) and poly ethylene glycol methyl ether methacrylate (PEGMEMA)/ethylene dimethacrylate (EDGMA). These hollow spheres exhibited higher loading of plasmid DNA polyplexes, as compared to solid ELP spheres, and induced greater expression of the model plasmid encoding GFP, as compared to both free plasmid DNA and DNA-loaded polyplexes. TEM imaging suggested that the hollow ELP spheres may enable endosomal escape, thereby protecting the DNA cargo from degradation and hence increasing the amount of intact DNA that is delivered to the cytosol. Furthermore, polyplexloaded hollow ELP spheres exhibited reduced cytotoxicity compared to polyplexes alone, demonstrating that this drug vehicle facilitated cellular uptake and intracellular delivery of gene cargo while also decreasing toxic side-effects typical of alternative gene carriers.

\section{Hyperthermia-targeted drug carriers}

\subsection{Tumor-targeted unimer aggregation}

The LCST behavior of ELPs can be triggered in vivo by an external thermal stimulus, providing an extrinsically controlled stimulus response that can be exploited for targeted delivery (Table 2). This approach for targeted delivery is particularly useful for cancer therapy, where a solid tumor can be locally heated to trigger the ELP phase transition only at the site of disease. Tuning the ELP phase transition to occur at temperatures of mild clinical hyperthermia $\left(40-44^{\circ} \mathrm{C}\right)[70]$ enables a clinically relevant external stimulus to be applied with spatial precision in patients using focused microwaves [71], radiofrequency [72], or ultrasound [73].

In its simplest application, the aggregation of ELP unimers can be exploited to target ELP accumulation to tumors by local hyperthermia. This was first observed with a fluorophorelabeled temperature-sensitive ELP unimer with a $\mathrm{T}_{t}$ of $\sim 40^{\circ} \mathrm{C}$ that was delivered systemically to mice bearing tumors implanted in a dorsal fold window chamber. The temperature-sensitive ELP formed aggregates in the vasculature of tumors heated to $42^{\circ} \mathrm{C}$ $\left(\mathrm{T}>\mathrm{T}_{\mathrm{t}}\right)$ that grew in size over the 50 min duration of imaging, as observed with fluorescence videomicroscopy [74]. These aggregates were not observed in tumors treated with temperature-sensitive ELP under normothermic conditions $\left(T<T_{t}\right)$ or in tumors treated with hyperthermia and a temperature-insensitive ELP control whose high $\mathrm{T}_{t}\left(>42^{\circ} \mathrm{C}\right)$ prevented its aggregation. Quantification of image fluorescence intensity confirmed that the tumor accumulation of temperature-sensitive ELP in hyperthermia treated tumors was approximately 2 -fold higher than in tumors at physiologic temperature [74, 75].

Enhanced accumulation was further confirmed by the quantification of ${ }^{14} \mathrm{C}$-labeled ELP in hyperthermia-treated subcutaneous xenografts on the mouse hind limb. Measurement of radioactivity in the mouse tumor confirmed a 1.8-fold increase in accumulation of temperature-sensitive ELP in heated tumors, as compared to temperature-sensitive ELP in tumors without heat, and a 1.5-fold increase in accumulation, as compared to temperatureinsensitive ELP in heated tumors [26]. Visualization of ${ }^{14} \mathrm{C}$-labeled ELP distribution in tumors by autoradiography revealed that temperature-sensitive ELP exhibited a more 
homogeneous distribution in the tumor, as compared to controls, suggesting that targeted ELP delivery by locally triggering ELP unimer aggregation can increase the overall accumulation and improve the spatial distribution of ELP in the tumor.

At the organ level, this temperature-induced accumulation is initiated by ELP aggregation in the tumor vasculature that increases the local concentration of ELP. Due to the reversible nature of the ELP transition, these aggregates dissolve upon cessation of tumor heating. The ELP resolubilization creates a steep concentration gradient, such that the ELP is then driven out by diffusion from regions of high concentration in the vasculature to regions of low concentration in the extravascular space. After $45 \mathrm{~min}$ of tumor hyperthermia, followed by 15 min of tumor cooling, temperature-sensitive ELP exhibited an increase in the rate of extravasation that accompanied the dissolution of the ELP aggregates (Figure 5) [76]. This effect was not seen with temperature-insensitive ELP. With tumor cooling, a 2.8-fold increase in tumor accumulation was achieved as compared to tumors without heat and a 1.6fold increase was achieved as compared to hyperthermia-treated tumors with temperatureinsensitive ELP. This boost in accumulation caused by heating and cooling suggests that accumulation could be further enhanced by thermal cycling, in which this process is repeated several times. Proof-of-concept of this approach was first shown by heating and cooling the tumor three times over $90 \mathrm{~min}$. ELP particles repeatedly formed with each round of hyperthermia, with only slight decrease in total particle mass with subsequent rounds of heating [76]. This approach may therefore serve to increase drug delivery by repeatedly creating a concentration gradient in the tumor vasculature that pumps the ELP carrier and its cargo into the extravascular space.

Visualization and quantification of temperature-triggered ELP accumulation in heated tumors indicated that the enhanced accumulation was dominated by ELP aggregation, while hyperthermia alone played a minor role, as determined by the accumulation of temperatureinsensitive ELP controls. The organ-level effects of hyperthermia, such as enhanced extravasation, act in combination with cell-level effects of hyperthermia, such as enhanced cellular internalization, to increase the accumulation observed in hyperthermia-treated tumors. This cell-level effect appeared to not be cell-type specific, as the enhanced accumulation of temperature-sensitive ELP in heated cells in vitro was observed in human ovarian carcinoma, squamous cell carcinoma, and cervical cancer cells [77]. Heat alone was not responsible for this increased internalization, as temperature-insensitive ELP showed lower cellular uptake than temperature-sensitive ELP in cells heated to $42^{\circ} \mathrm{C}$.

It is likely that enhanced cellular uptake of temperature-sensitive ELP is induced by formation of nanoparticle aggregates with increased hydrophobicity, which are readily taken up by endocytosis. However, it is unlikely that cells can endocytose larger micron-scale aggregates. This enhanced cellular uptake induced by the ELP transition can furthermore be conferred to other drug delivery vehicles, as demonstrated by ELP-functionalized PEGylated liposomes that achieved greater cellular uptake above the ELP $\mathrm{T}_{t}$, as compared to below the $T_{t}$ or as compared to PEGylated liposomes alone [78]. Thus, the triggered hydrophobic aggregation of ELP can even overcome the hydrophilic sheathing effect of PEG coatings that tends to decrease cellular uptake of PEG-functionalized carriers. 
Thermally enhanced uptake of temperature-sensitive ELPs can be further amplified by functionalizing the ELP with cell-penetrating peptides (CPPs), which promote non-specific cellular uptake of attached cargo by endocytic mechanisms. CPP-ELPs were previously shown to increase cellular uptake, as compared to a non-functionalized ELP control [43], but when the $T_{t}$ of these unimer CPP-ELPs was tuned to occur between physiologic temperature and mild hyperthermia the intracellular uptake could be further enhanced by the ELP transition. For a penetratin-ELP fusion, hyperthermia-induced aggregation at $42^{\circ} \mathrm{C}$ increased cellular uptake by 13 -fold, as compared to cells treated at $37^{\circ} \mathrm{C}$ [79]. This increased intracellular delivery enhanced the efficacy of a genetically fused c-Myc inhibitor peptide drug (H1), inducing 2-fold greater cell death when delivered by temperature-sensitive ELP to hyperthermia-treated cells, as compared to non-heated cells or cells treated with a temperature-insensitive ELP that did not aggregate. This approach to hyperthermia-assisted cellular uptake for peptide drug delivery has also been exploited for the in vitro delivery of H1 c-Myc inhibitor peptide by Bac-ELP [80], p21 kinase inhibitor peptide by Bac-ELP [81], L12 cancer cell lytic peptide by TAT-ELP [82], and GRG mRNA splicing inhibitor by SynB1-ELP [83]. However, not all of these CPP-ELPs were found to be suitable as drug carriers due to their inherent toxicity in some cell lines [80, 84].

Hyperthermia-assisted intracellular delivery of peptide drugs with CPP-ELPs was further combined with hyperthermia-targeted accumulation in vivo to improve anti-cancer outcomes in rodent models. The delivery of the H1 peptide by Bac-ELP was shown to effectively reduce tumor burden in mammary pad breast tumors, following intraperitoneal administration [85], and also demonstrated increased tumor accumulation and prolonged survival in a model of rat glioma, following intravenous administration [86]. In both applications, four cycles of tumor heating and cooling enhanced local tumor accumulation of temperature-sensitive CPP-ELPs and improved therapeutic response, as compared to tumors that were not heated.

Hyperthermia-targeted CPP-ELPs have similarly been used to deliver small molecule drugs. Hyperthermia-assisted intracellular drug delivery of doxorubicin conjugated to TAT-ELP via a cathepsin cleavable GFLG linker $[46,87]$ and paclitaxel conjugated to SynB1-ELP via an acid cleavable hydrazone linker [88] have been investigated in vitro for anti-cancer applications. Furthermore, delivery of doxorubicin conjugated to SynB1-ELP via an acid cleavable hydrazone linker was shown to have efficacy against murine breast cancer tumors in vivo, such that the increased cellular uptake [89], prolonged circulation time, enhanced tolerated dose, and increased drug accumulation in the tumor [90] led to a decrease in tumor burden for mice treated with hyperthermia-targeted ELP drug carrier as compared to animals not receiving hyperthermia treatment or animals treated only with free drug [89, 90].

\subsection{Tumor-targeted unimer-to-micelle transition}

ELP unimer aggregation increases local accumulation by inducing the thermally triggered coacervation of an ELP into micron-scale aggregates in the heated tumor. Alternatively, the transition of an $\mathrm{ELP}_{\mathrm{BC}}$ from unimer to micelle may be used to enhance interactions with the tumor, as self-assembled ELP nanoparticles can function as a nanoscale scaffold to selectively display bioactive functionalities on their exterior. $\mathrm{ELP}_{\mathrm{BC}}$ that are functionalized 
with peptide ligands of cell-surface receptors on their hydrophilic terminus have been developed in an approach that has been termed temperature-triggered multivalent affinity targeting. The ligands appended to these $\mathrm{ELP}_{\mathrm{BC}} \mathrm{s}$ were chosen due to their low affinity toward receptors typically overexpressed on tumor-related endothelium. Assembly of the $E P_{B C} S$ into spherical micelles greatly enhances the local density of the ligand on the micelle corona, which increases the avidity toward the targeted receptor and can potentially lead to increased tumor accumulation and enhanced tumor cell uptake of the $\operatorname{ELP}_{\mathrm{BC}}$ carrier. This temperature-triggered approach can thus provide a mechanism of enhancing receptortargeted uptake in the tumor, while avoiding off-target interactions in healthy tissues.

Proof-of-concept of temperature-triggered multivalent affinity targeting was first shown with $\mathrm{ELP}_{\mathrm{BC}}$ s functionalized with either a NGR peptide that targets the CD13 receptor [47], or a RGD peptide that targets the $\alpha_{v} \beta_{3}$ integrin [91]. These targets were chosen because they are overexpressed on angiogenic tumor vasculature. Both peptide-functionalized $E \mathrm{P}_{\mathrm{BC}} \mathrm{S}$ exhibited greater uptake by cells overexpressing their respective target receptors in their micellar state, as compared to their unimer state. This effect was mediated by the modulation of ligand multivalency, as uptake of non-functionalized ELP $_{\mathrm{BC}}$ did not increase upon temperature-triggered micelle assembly. Additionally, the defined spatial organization of the peptide functionalization on the micelle corona was imperative for maximizing uptake by affinity modulation in the case of RGD-ELP $\mathrm{BC}_{\mathrm{B}} \mathrm{S}$, as the disordered aggregation of RGDfunctionalized single segment ELP, which forms polydisperse micron-scale aggregates above its $\mathrm{T}_{\mathrm{t}}$, did not result in increased cellular uptake comparable to RGD-ELP $\mathrm{BC}_{\mathrm{BC}}$ micelles.

The functionalization of $\mathrm{ELP}_{\mathrm{BC}} \mathrm{S}$ with larger protein ligands has similarly been shown to promote temperature-triggered uptake via self-assembly. Fusion of a fibronectin type III domain (Fn3), an $\alpha_{v} \beta_{3}$ receptor ligand, to the hydrophilic terminus of an $E_{L P} P_{B C}$ did not perturb temperature-triggered micelle assembly, despite the hydrophobicity and size (approximately $10 \mathrm{kDa}$ ) of this protein. Above the CMT, the Fn3 was presented multivalently on the micelle corona, and showed enhanced uptake by human leukemia cells overexpressing the $\alpha_{v} \beta_{3}$ receptor, as compared to cells maintained at a temperature below the CMT. This effect was not observed in wild-type cells with low-level $\alpha_{\mathrm{v}} \beta_{3}$ expression [92].

The extrinsic control over micelle assembly can also be applied to non-specific, receptorindependent mechanisms of uptake to provide a method of targeted internalization that is entirely independent of tumor cell type. This approach was demonstrated with CPPfunctionalized $\mathrm{ELP}_{\mathrm{BC}} \mathrm{s}$, where the low density of a single arginine-rich CPP $\left(\operatorname{Arg}_{5}\right)$ appended to the $\mathrm{ELP}_{\mathrm{BC}}$ 's hydrophilic domain minimized uptake in the unimer state, while the enhanced density of arginine-rich CPP on the micelle corona after self-assembly significantly enhanced cellular uptake [93]. By optimization of the sequence and size of the $\mathrm{ELP}_{\mathrm{BC}}$ domains, the self-assembly of this $\mathrm{Arg}_{5}-\mathrm{ELP}_{\mathrm{BC}}$ was tuned to occur at a CMT of approximately $40^{\circ} \mathrm{C}$, between physiologic temperature and $42^{\circ} \mathrm{C}$ typical for mild hyperthermia of solid tumors, allowing temperature-triggered cellular uptake to be controlled by a clinically relevant trigger. Varying the CPP-functionalization of the ELP $_{\mathrm{BC}}$ modulated the level of cellular uptake below and above the CMT, such that intracellular delivery could be tuned to achieve controlled therapeutic efficacy following delivery of drug 
cargo. For example, $\mathrm{Arg}_{8}$-functionalized $\mathrm{ELP}_{\mathrm{BC}}$ appended with a proapoptotic $\mathrm{BH} 3$ peptide drug through an enzyme-cleavable linker demonstrated controlled cytotoxicity in vitro, where significant cell death was induced by enhanced intracellular drug delivery at $42^{\circ} \mathrm{C}$, while cells at $37^{\circ} \mathrm{C}$ were spared [94]. This approach therefore extends the concept of affinity ligand modulation for receptor targeting, such that modulation of the local interfacial density of CPPs can control receptor-independent intracellular drug delivery by a clinically feasible thermal stimulus.

\subsection{Tumor-targeted micelle aggregation}

There are limitations when exploiting the transition of systemically delivered ELP unimers for drug delivery that can be overcome by the delivery of temperature-sensitive ELP selfassemblies. One major limitation of ELP unimers is the strong concentration dependence of their $T_{t}$, such that a decrease in concentration leads to an increase in $T_{t}$. For systemically delivered ELP unimers, this change in $T_{t}$ with dilution requires careful analysis of plasma clearance, such that the concentration of ELP unimers in circulation will exhibit the desired $T_{t}$ over the course of tumor heating. In contrast, self-assembled ELP nanoparticles exhibit a nearly constant $T_{t}$ over a large concentration range [53].

ELP nanoparticle assemblies driven by doxorubicin conjugation, discussed in Section 2.3, retained the thermal properties of their ELP component, such that doxorubicin-ELP micelles exhibited temperature-triggered aggregation into micron-scale coacervates. The $T_{t}$ of doxorubicin-ELP micelle aggregation was tuned to occur between physiologic temperature and mild hyperthermia by manipulating the hydrophobicity of the ELP's guest residues, such that temperature-triggered aggregation of doxorubicin-ELP micelles occurred within a narrow temperature window $\left(39-42^{\circ} \mathrm{C}\right)$ across a wide range of concentration $(1-100 \mu \mathrm{M})$ [95]. This near insensitivity of $T_{t}$ to concentration, as compared to the strong concentration dependence of ELP unimer $T_{t} s$, is attributed to the highly conserved local ELP concentration in each micelle. This feature of micelle aggregation should thus allow the delivery of ELP nanoparticles whose thermal behavior is predictable over a range of concentrations encountered in systemically administered drug carriers that are cleared from the circulation over time.

Consistent with in vivo experiments exploiting ELP unimer aggregation, temperaturetriggered aggregation of doxorubicin-ELP micelles achieved increased accumulation in hyperthermia-treated tumors implanted on the mouse hind limb. A hyperthermia cycle schedule of 10 minutes tumor heating followed by 10 minutes tumor cooling repeated six times maximized tumor accumulation as compared to non-heated tumors or tumors receiving an equivalent 60 minutes of continuous heating. Temperature-sensitive doxorubicin-ELP micelles showed 2.6-fold greater tumor accumulation in hyperthermiacycled tumors, as compared to non-heated tumors, and approximately 1.6-fold greater tumor accumulation as compared to temperature-insensitive micelles in hyperthermia-cycled tumors [96]. These doxorubicin-ELP micelles are thus a promising system that can provide advantages of both nanoparticle drug carriers and thermally targeted drug delivery by externally focused mild hyperthermia. 


\section{Therapeutic ELP depots}

\subsection{ELP depots for applications in cancer}

Due to their tunable phase transition, ELPs are a natural choice for temperature-triggered depot formation in a variety of applications for the local and sustained delivery of therapeutics (Table 3). Cancer is one such application where prolonged local drug exposure within the tumor can significantly increase therapeutic efficacy while also avoiding systemic toxicity. Local tumor therapy has been explored with ELP-radionuclide conjugates that form a depot by coacervation of the ELP at body temperature. These ELPs, designed to have a $T_{t}$ below $37^{\circ} \mathrm{C}$, are injected as soluble unimers into a tumor, and form a depot in situ because of their temperature-triggered coacervation. Local administration of ${ }^{125} \mathrm{I}$-labeled ELP depots prolonged the residence of radionuclide in murine tumors, as compared to a temperature-insensitive ELP control that remained soluble at body temperature [97]. Furthermore, the ELP depot decreased dehalogenation of the conjugated radionuclide, likely due to the reduced accessibility of dehalogenase enzymes to the ELP coacervate. This advantage of the ELP depot could further contribute to the prolonged local residence of the radionuclide within the tumor. ${ }^{131}$ I-labeled ELP depots achieved significantly improved tumor regression and survival in murine xenograft tumors, as compared to a soluble ELP control, however this particular ELP depot did not achieve complete tumor regression.

The design of an ELP depot for local tumor radiation therapy was further optimized by controlling the ELP $T_{t}$ with manipulation of the ELP injection concentration, chain length, and composition, where the ELP composition was changed by appending the ELP Cterminus with increasing number of tyrosine residues, which served as both reactive residues for iodine conjugation and as hydrophobic moieties to depress the ELP $\mathrm{T}_{\mathrm{t}}$. Tumor retention of ${ }^{125}$ I-labeled ELP was prolonged with increasing injection concentration, increasing chain length, and increasing number of tyrosine residues (Figure 6) [98]. Increasing the ELP chain length from 60 to 120 pentapeptides significantly prolonged tumor retention, but the additional increase in length to 240 pentapeptides resulted in only slight increase in tumor retention that did not justify the increased ELP dosage that would be required of this high MW construct. Furthermore, the incorporation of seven tyrosine residues was found to maximize retention, as an increasing number of these hydrophobic residues depressed the ELP $T_{t}$. The effect of these parameters strongly suggested that tumor retention correlates with a decrease in the ELP $T_{t}$. This allowed selection of an optimal ELP with a length of 120 pentapeptides $(50 \mathrm{kDa})$, functionalized with seven tyrosine residues, which was delivered at a concentration of $1000 \mu \mathrm{mol} / \mathrm{L}$. This optimized ELP was labeled with ${ }^{131} \mathrm{I}$ and demonstrated $100 \%$ response and over $67 \%$ complete regression over 60 days in two xenografts-FaDu squamous cell carcinoma and PC-3 prostate cancer-implanted subcutaneously on the mouse hind limb.

Prolonged retention is a primary concern for local drug delivery depots in the tumor; however, distribution of the depot and its drug cargo throughout the tumor tissue also has important implications on the anti-cancer efficacy of local drug delivery. Slower kinetics of depot gelation, as compared to the rapid gelation achieved by temperature-triggered ELP coacervation, may provide improved tumor distribution if spreading of the injected ELP 
occurs throughout the tumor prior to gelation. This approach has been investigated with ELPs that incorporate multiple cysteine residues along the ELP backbone that can participate in ELP cross-linking by formation of inter chain disulfides to create a stable ELP depot. Because disulfide formation is slow, cross-linking between cysteines was accelerated by the co-injection of $0.3 \mathrm{wt} \%$ hydrogen peroxide, which led to a gelation time of approximately 2.5 min [99]. Intratumoral delivery of ${ }^{125}$ I-labeled cysteine-containing ELP and hydrogen peroxide led to prolonged tumor retention, and near-infrared imaging of fluorophore-labeled cysteine-containing ELPs revealed a more homogenous distribution throughout $\mathrm{FaDu}$ xenografts on the mouse leg $8 \mathrm{~h}$ after intratumoral injection, as compared to the cysteine-containing ELP delivered without the oxidant. This gelation technique furthermore showed promise as a mechanism for prolonged therapeutic delivery, as gelation of a mixture of ELP, hydrogen peroxide, and the model protein BSA achieved prolonged BSA release ex vivo, with complete release achieved in 5 days, while ELPs lacking cysteines showed much faster BSA release. This alternative technique of ELP gelation may thus provide therapeutic benefits by providing prolonged exposure to drug homogeneously throughout the tumor tissue.

\subsection{ELP depots for applications in joint degeneration}

ELP depots provide an advantageous route of drug delivery to sites in the body that cannot easily be reached by systemic administration. One such application is the treatment of degenerative joint diseases, such as osteoarthritis, as joints are composed primarily of avascular tissue and are thus not easily accessible from systemic circulation. ${ }^{14} \mathrm{C}$-labeled ELP depots delivered by intra-articular injection exhibited a half-life in the rat knee joint over $85 \mathrm{~h}$, far exceeding the half-life of less than $4 \mathrm{~h}$ exhibited by a soluble ELP control [100]. Furthermore, the levels of ${ }^{14} \mathrm{C}$-labeled ELP in the blood remained lower for ELP aggregates than soluble ELPs. An ELP depot can therefore provide advantages of both prolonged local presence in the joint and decreased systemic exposure to the ELP carrier.

Application of ELP depots for drug delivery in the joint has been explored by the thermal gelation of an ELP fusion with the anti-inflammatory interleukin-1 receptor antagonist (IL-1Ra). The IL-1Ra ELP fusion retained bioactivity, although binding of the fusion protein to the IL-1 receptor was weaker than the binding of free IL-1Ra. However, the IL-1Ra ELP fusion could moderate inflammatory processes such as IL-1 stimulated proliferation in vitro, albeit at higher protein concentrations than IL-1Ra alone [101]. Proteolytic degradation of the ELP by tissue enzymes, such as collagenase, appeared to liberate IL-1Ra that demonstrated superior bioactivity compared to the full IL-1Ra ELP fusion. A local depot of IL-1Ra ELP fusions thus has the potential to prolong the local presence of IL-1Ra and release free IL-1Ra within the joint as the depot is proteolytically degraded.

As an alternative to depot formation purely through thermal gelation, covalent cross-linking of ELPs can also be used to create drug-loaded formulations that may be locally injected while retaining their temperature-responsive properties. This approach was investigated for the delivery of small molecule antibiotics vancomycin and cefazolin, as local delivery of antibiotics is often necessitated by surgical orthopedic interventions. An ELP containing 
periodic lysine residues was cross-linked by $\beta$-[Tris(hydroxymethyl) phosphine] proprionic acid (THPP), creating a porous ELP network [102]. Lyophilized cross-linked ELPs were loaded with drug by rehydration in antibiotic solutions. Antibiotics released from the thermally triggered depots of cross-linked ELPs retained their activity against Bacillus subtilis. In the case of vancomycin delivery, the rate of antibiotic release could be controlled by the ELP concentration, where higher ELP concentration led to slower release of drug. Covalently cross-linked ELP depots thereby provide an alternative approach for the sustained delivery of physically loaded small molecule therapeutics from thermally responsive ELP hydrogels.

\subsection{ELP depots for applications in neuroinflammation}

Neuroinflammation is another pathological target in which local treatment is useful to improve anti-inflammatory therapeutic outcomes and avoid systemic side effects. Temperature-triggered aggregation of ELP depots has been investigated for prolonged local drug delivery proximal to the dorsal root ganglion. ELP depots increased the half-life of tritium-labeled ELP at the perineural site and decreased the fraction of ELP that was released into circulation, as compared to a soluble ELP control [103]. Since TNFa is one of the primary drivers of local neuroinflammation, inactivating $\mathrm{TNFa}$ is a valuable route of treatment. However, TNFa-directed drugs are often accompanied with dangerous off-target side effects, including immunosuppression. Local delivery is therefore advantageous for therapeutics such as soluble tumor necrosis factor receptor type II (sTNFRII), which binds to and thereby inactivates TNFa. A recombinant sTNFRII ELP fusion exhibited TNFa binding, albeit at attenuated levels compared to free sTNFRII [104]. In rat dorsal root ganglion explants with artificial inflammation stimulated by TNFa, sTNFRII ELP depots reversed inflammatory responses, as seen by recovery in the balance of pro- and antiinflammatory cytokines, IL-6 and IL-10 [105]. The trade-off between lower bioactivity of the sTNFRII ELP fusion and longer residence time at the site of inflammation, as compared to free protein, ultimately must be investigated in vivo, where advantages of prolonged local residence and decreased systemic exposure could lead to better therapeutic outcomes for an ELP fusion depot as compared to free drug.

Neuroinflammation can alternatively be treated with ELPs covalently conjugated to small molecule therapeutics. Curcumin, a small molecule drug that also antagonizes TNFa function, was conjugated to ELPs containing periodic reactive glutamate residues via a degradable carbamate linker. Activity of curcumin in the ELP depot was largely conserved, as compared to free drug, when measured by in vitro protection against TNFa-mediated cytotoxicity [106]. Curcumin ELP depots placed near the sciatic nerve by intramuscular injection retained 5-fold higher levels of curcumin at 96 hours, as compared to free drug. Furthermore, the ELP depots reduced systemic exposure of the drug as the plasma pharmacokinetics for curcumin ELP depots had 7-fold lower area under the curve than free drug. The preliminary evaluation of this approach further suggests that thermally responsive ELP depots can serve to retain drug at the delivery site, regardless of drug cargo type. 


\subsection{ELP depots for applications in diabetes}

An ELP depot does not have to reside at the site of disease to provide a therapeutic effect. This has been demonstrated by subcutaneous drug depots for the control of type 2 diabetes. Peptide drugs such as glucagon-like peptide 1 (GLP-1) have shown promise for the treatment of type 2 diabetes, but their fast plasma clearance and rapid enzymatic degradation necessitate frequent administration to achieve therapeutic efficacy. A recombinant fusion of GLP-1 and ELP can form an injectable depot if the ELP's $T_{t}$ is tuned below body temperature. Upon slow dissolution of the GLP-1 ELP fusion depot the ELP then provides a long-circulating macromolecular carrier for its peptide drug cargo. Fluorophore-labeled GLP-1 ELP fusion depots were retained at the subcutaneous site of administration in the mouse torso over the course of 5 days, as visualized by near-infrared imaging (Figure 7) [107]. In C57BL/6 J mice this prolonged residence of a single subcutaneous injection of depot forming GLP-1 ELP fusion reduced fed glucose levels approximately $30 \%$ for 5 days. This outcome differed greatly from free GLP-1 and GLP-1 ELP fusions that did not aggregate at body temperature, as these soluble controls resulted in a rapid decrease in fed glucose levels that was not sustainable. This approach confirmed that GLP-1 could retain its therapeutic bioactivity when fused to an ELP, while achieving prolonged therapeutic effects by fusion to a depot-forming macromolecular carrier.

Alternatively, GLP-1 can be genetically fused to a depot-forming ELP in a way that provides prolonged release of free GLP-1 peptide. This has been achieved by a system called protease operated depots (PODs) in which the GLP-1 peptide is oligomerized and fused to an ELP with arginine residues placed between the GLP-1 repeats, such that proteolytic cleavage at the arginine residues releases GLP-1 from the depot into the subcutaneous space. A POD with six GLP-1 repeats on each ELP demonstrated reduced glucose levels over 5 days, significantly longer than the duration of glucose control achieved with a soluble ELP control (6 h) or free GLP-1 alone (1 h) [108]. Thermally responsive ELP fusions can thus provide multiple mechanisms of peptide drug delivery, as either depots for prolonged release of peptide ELP fusions, or as depots that provide sustained release of free peptide drug.

\section{ELP-functionalized hybrid drug delivery systems}

\subsection{ELP-functionalized plasmonic nanoparticles}

The controlled synthesis and stimulus-response of ELPs alone have been exploited for a multitude of applications in drug delivery. However, ELPs can also serve as useful components in other drug delivery systems, by conferring stimuli-response to other materials (Table 4). One example of these hybrid systems is ELP-functionalized plasmonic nanoparticles. ELP-functionalized gold nanoparticles were first created by ELP adsorption onto mercaptoundecanoic acid (MUA)-modified spherical gold nanoparticles [109]. The thermal response of the ELPs was conferred to the hybrid particles, such that the ELPfunctionalized gold nanoparticles reversibly aggregated in solution when the ELP transition was triggered by an increase in temperature. The ELP aggregation could be monitored by inter-particle plasmon coupling, as aggregation resulted in a red shift in the nanoparticle absorbance likely due to decreased inter-nanoparticle distances in the aggregates as 
compared to soluble nanoparticles in solution. A similar effect was observed when the ELP was covalently attached to the particle surface by coupling an amine group on the ELP's Nterminus to the activated MUA surface on the gold nanoparticles [110]. However, adsorbed and covalently grafted ELP showed differences in the reversibility of thermally triggered aggregation, as the aggregation achieved with covalently grafted ELPs was less reversible than the aggregation achieved with adsorbed ELPs [109].

The unique stimulus-response of gold nanoparticles can also contribute to the behavior of these hybrid assemblies, such that the plasmon resonance of gold nanoparticles can be exploited to heat the particles in response to illumination and thereby trigger the local aggregation of covalently attached ELPs. This approach has been explored with an ELP containing two cysteine guest residues that allowed coupling to gold nanorods by chemisorption of the thiols onto the gold nanorod surface [111]. The local plasmon resonance of the nanorods resulted in heating of the particles in response to illumination with near-infrared light. This light-induced heating of the gold nanorods in turn triggered the phase transition of the attached ELPs. Thus, in this hybrid system the ELP transition was optically triggered, such that illumination in the near-infrared ultimately induced aggregation of the ELP-decorated nanorods.

Increasing the number of cysteines in the ELP sequence resulted in ELP-functionalized gold nanorod assemblies that exhibited a similar ELP transition in response to near-infrared illumination. However, after aggregation at temperatures above the ELP $\mathrm{T}_{t}$, these assemblies did not reversibly disassemble, likely due to the increased cysteine content that encouraged extensive cross-linking between the ELP-functionalized gold nanorods. These cysteine-rich ELP-functionalized gold nanorods hence formed stable composite matrices at temperatures below the ELP $\mathrm{T}_{\mathrm{t}}$ (approximately $31^{\circ} \mathrm{C}$ ) while retaining their thermal responsiveness upon subsequent excitation of the nanorods with near-infrared illumination [112].

These composite coacervates provided an interesting combination of both thermal and chemotherapeutic therapy when the heat-shock protein 90 inhibitor 17-(allylamino)-17demethoxygeldanamycin (17-AAG) was encapsulated by physical mixing prior to coacervation of the ELP-functionalized gold nanorod matrix. Minimal release of drug was observed by diffusion alone, but near-infrared laser illumination of the ELP-gold nanorod composite matrix led to significant drug release due in part to the thermal response of the ELP, presumably because the phase transition of the ELP led to desolvation-driven expulsion of the encapsulated 17-AAG. $90 \%$ of prostate cancer cells cultured on drugloaded ELP-functionalized gold nanorod matrices were killed by the combination effects of hyperthermia and the triggered release of heat shock protein inhibitor 17-AAG (Figure 8). In contrast, laser illumination without drug resulted in less than $10 \%$ cell death that was spatially confined to the spot of laser illumination [112]. This approach thus provides a mechanism to exploit hyperthermia induced by near-infrared illumination for drug release from a stimulus-responsive composite matrix.

\subsection{ELP-functionalized liposomes}

ELPs can also be used to endow temperature-triggered drug release from drug carriers such as liposomes. Fatty-acid-functionalized ELPs permit the decoration of these carriers by 
insertion into the bilayer of PEGylated liposomes. The close proximity of the ELP to the lipid bilayer causes temperature-induced changes of ELP conformation to destabilize the membrane and release liposomal contents. Doxorubicin-loaded PEGylated liposomes functionalized with short ELPs (three pentapeptides in length) exhibited stable drug encapsulation at physiologic temperatures, due in part to the incorporation of cholesterol and fatty-acid ELP that decreased fluidity of the liposome bilayer, while providing rapid drug release above the ELP $\mathrm{T}_{t}$, which was tuned between $39-42^{\circ} \mathrm{C}$ for hyperthermia-targeted drug delivery [113]. Less than $20 \%$ of loaded doxorubicin was released from ELPfunctionalized liposomes at $37^{\circ} \mathrm{C}$, while greater than $95 \%$ was released at $42^{\circ} \mathrm{C}$. In vitro, this resulted in the nuclear delivery of doxorubicin in HeLa cells only when treated at $42^{\circ} \mathrm{C}$. Alternatively, temperature-sensitive lysolipid liposomes, which release drug in response to phase transition of the lipid membrane, exhibited greater instability and less defined drug release, such that more drug was lost at $37^{\circ} \mathrm{C}$ and less drug was released at $42^{\circ} \mathrm{C}$, as compared to ELP-functionalized PEGylated liposomes. The enhanced stability of ELPfunctionalized liposomes likely contributed to their prolonged circulation and increased tumor accumulation in vivo, while the enhanced temperature-triggered drug release led to improved drug delivery at the site of the tumor. These factors resulted in slightly enhanced anti-cancer activity in subcutaneous murine tumors treated with hyperthermia and intravenously administered ELP-functionalized doxorubicin-loaded PEGylated liposomes as compared to doxorubicin-loaded lysolipid liposomes.

As an alternative to concurrent delivery of ELP-decorated liposomes and tumor hyperthermia, functionalization of liposomes with an ELP can promote tumor-targeted intracellular localization that can then be followed by hyperthermia-triggered drug release. Cyclic RGD, a ligand for the $\alpha_{v} \beta_{3}$ integrin that is upregulated in the angiogenic vasculature of many tumors, was appended to PEGylated liposomes containing fatty-acid functionalized ELPs and induced increased cellular uptake of doxorubicin cargo as compared to ELPfunctionalized PEGylated liposomes without RGD [114]. Hyperthermia was only applied after a period in which the liposomes were allowed to interact with the cell surface and potentially induce endocytosis. Hyperthermia-mediated drug release after intracellular accumulation of RGD-decorated ELP-functionalized PEGylated liposomes led to enhanced cell death in vitro, as compared to both ELP-functionalized PEGylated liposomes with hyperthermia but lacking RGD, and RGD-decorated ELP-functionalized PEGylated liposomes without heat. Increased tumor accumulation at physiological temperature of intravenously administered RGD-decorated ELP-functionalized PEGylated liposomes, as compared to ELP-functionalized PEGylated liposomes lacking the RGD ligand, further supported the potential of this approach for increasing local drug delivery with temperatureresponsive intracellular drug release.

\subsection{ELP-functionalized dendrimers}

Stimulus-responsive behavior can also be endowed to dendrimer drug carriers by ELPfunctionalization. Conjugation of $(\mathrm{VPGVG})_{1}[115,116]$ or $(\mathrm{VPGVG})_{4}[116]$ to the amine terminus of a generation-4 polyamidoamine (PAMAM) dendrimer conferred the thermal response of ELPs to this hybrid carrier. The ELP component alone did not exhibit aggregation upon heating [115], likely due to the extremely small MW of the ELP, which is 
consistent with the fact that the $T_{t}$ of ELPs follows an inverse dependence on the ELP chain length. However, the high density of ELP pentapeptides on the dendrimer recapitulated the observed thermal response typical of much larger ELPs, such that the ELP-functionalized dendrimer displayed thermally triggered aggregation, suggesting that there is an additive effect on the $T_{t}$ of short ELP segments that are packed at an interface with high local density. Furthermore, the thermal response of the ELP dendrimers was influenced by salt [115] and $\mathrm{pH}[115,116]$, demonstrating that ELP-functionalization of dendrimers could confer responsiveness to multiple stimuli. The model drug rose bengal was encapsulated in $(\mathrm{VPGVG})_{1}$-functionalized dendrimers and exhibited release rates over 24 hours, equivalent to those achieved by the dendrimer alone [115]. These results suggest that ELPfunctionalization may provide stimulus-responsive behavior to dendrimers while retaining the dendrimers' capacity as drug carriers.

\section{Conclusions, future directions, and challenges}

ELPs are biologically inspired materials whose LCST behavior make them useful biopolymers for stimulus-responsive applications in biological settings. Their genetically encoded design has enabled the production of homogeneous monodisperse polypeptides in a variety of architectures, which serve a range of applications in drug delivery. ELPs have been employed as soluble macromolecular carriers, nano- and microparticle vehicles, and macroscopic local depots. Their stimulus-response has been exploited for purification of peptide and protein drugs, triggered drug release, disease targeting, sustained drug retention, and prolonged drug delivery.

The ease with which diverse ELPs can be genetically designed and recombinantly produced will continue to stimulate their use in drug delivery. There are several areas that are particularly exciting in considering the future of ELPs as drug delivery vehicles. First, the recombinant synthesis of ELPs will provide a wealth of opportunities for growth, as advancements in molecular biology techniques can be translated to this class of biologic materials. New methods of ELP gene synthesis, expression, and functionalization are thus imaginable by means of novel techniques in recombinant cloning, translation, and posttranslational modification. Advances in techniques of incorporating unnatural amino acids into biopolymers, for example, may be applied to ELP synthesis to introduce new functional properties beyond those endowed by the natural library of amino acids [117-119]. Second, the morphologies of ELPs exploited for drug delivery will realize a growing diversity as we obtain a greater understanding of the parameters that can drive ELP selfassembly. Structures such as vesicles [120], nanofibers [121], and nanoworms [122] have already been observed with vehicle systems containing an ELP component. Advances in the de novo design of such morphologies by experimental determination—or alternatively, theoretical prediction - of the phase diagrams of these systems is critical because it will allow the a priori design, at the amino acid sequence level, of drug carriers with tunable sizes and morphologies. Third, exploring new peptide polymers that go beyond the current sequence space of the ELP pentapeptide repeat will reveal new materials with properties that expand upon the reversible LCST behavior of the majority of ELPs that currently exist in the field. For example, biopolymers that exhibit tunable hysteresis in their LCST driven aggregation behavior [12] and biopolymers that exhibit tunable upper critical solution 
temperature phase transition behavior (unpublished data) are two examples of novel behaviors that are beginning to emerge as we look beyond the standard framework of the $(\mathrm{VPGXG})_{\mathrm{n}}$ repeat. Finally, a more detailed exploration of hybrid drug delivery systems thatcombine ELPs with synthetic moieties by exploiting emerging approaches in chemical biology will further extend the functionality of ELPs, resulting in new designs of delivery vehicles.

At the same time, challenges still remain in the clinical translation of this class of materials, as an ELP carrier is yet to receive clinical approval for applications in drug delivery, though an ELP fusion with a peptide drug has successfully completed a phase 2 clinical trial. One challenge in the clinical translation of ELPs—and indeed all peptide derived materials-is their potential to trigger an unfavorable immune response. Despite these concerns, ELP drug carriers for treatment of diabetes and heart disease are successfully progressing toward the clinic, as preliminary clinical trials have demonstrated that ELPs are well tolerated in humans and do not induce a significant immune response in most individuals. We believe ELP drug carriers — and more broadly, peptide polymers — have a bright future as building blocks of molecularly engineered drug delivery systems.

\section{Acknowledgments}

This work was supported by funding from the NIH (R01EB007205) and by the NSF's Research Triangle MRSEC (DMR-1121107).

\section{References}

1. Tatham AS, Shewry PR. Elastomeric proteins: biological roles, structures and mechanisms. Trends Biochem. Sci. 2000; 25:567-571. [PubMed: 11084370]

2. Urry DW. Physical chemistry of biological free energy transduction as demonstrated by elastic protein-based polymers. J. Phys. Chem. B. 1997; 101:11007-11028.

3. McDaniel JR, Radford DC, Chilkoti A. A unified model for de novo design of elastin-like polypeptides with tunable inverse transition temperatures. Biomacromolecules. 2013; 14:28662872. [PubMed: 23808597]

4. Urry DW, Luan CH, Parker TM, Gowda DC, Prasad KU, Reid MC, Safavy A. Temperature of polypeptide inverse temperature transition depends on mean residue hydrophobicity. J. Am. Chem. Soc. $1991 ; 113: 4346-4348$.

5. Urry DW. The change in Gibbs free energy for hydrophobic association: derivation and evaluation by means of inverse temperature transitions. Chem. Phys. Lett. 2004; 399:177-183.

6. Meyer DE, Chilkoti A. Quantification of the effects of chain length and concentration on the thermal behavior of elastin-like polypeptides. Biomacromolecules. 2004; 5:846-851. [PubMed: 15132671]

7. Cho YH, Zhang YJ, Christensen T, Sagle LB, Chilkoti A, Cremer PS. Effects of hofmeister anions on the phase transition temperature of elastin-like polypeptides. J. Phys. Chem. B. 2008; 112:13765-13771. [PubMed: 18842018]

8. Mackay JA, Callahan DJ, Fitzgerald KN, Chilkoti A. Quantitative model of the phase behavior of recombinant $\mathrm{pH}$-responsive elastin-like polypeptides. Biomacromolecules. 2010; 11:2873-2879. [PubMed: 20925333]

9. Callahan DJ, Liu W, Li X, Dreher MR, Hassouneh W, Kim M, Marszalek P, Chilkoti A. Triple stimulus-responsive polypeptide nanoparticles that enhance intratumoral spatial distribution. Nano Lett. 2012; 12:2165-2170. [PubMed: 22417133] 
10. Meyer DE, Chilkoti A. Genetically encoded synthesis of protein-based polymers with precisely specified molecular weight and sequence by recursive directional ligation: Examples from the elastin-like polypeptide system. Biomacromolecules. 2002; 3:357-367. [PubMed: 11888323]

11. McDaniel JR, Mackay JA, Quiroz FG, Chilkoti A. Recursive directional ligation by plasmid reconstruction allows rapid and seamless cloning of oligomeric genes. Biomacromolecules. 2010; 11:944-952. [PubMed: 20184309]

12. Amiram M, Quiroz FG, Callahan DJ, Chilkoti A. A highly parallel method for synthesizing DNA repeats enables the discovery of 'smart' protein polymers. Nat. Mater. 2011; 10:141-148. [PubMed: 21258353]

13. Sallach RE, Conticello VP, Chaikof EL. Expression of a recombinant elastin-like protein in Pichia pastoris. Biotechnol. Prog. 2009; 25:1810-1818. [PubMed: 19827084]

14. Schipperus R, Teeuwen RL, Werten MW, Eggink G, de Wolf FA. Secreted production of an elastin-like polypeptide by Pichia pastoris. Appl. Microbiol. Biotechnol. 2009; 85:293-301. [PubMed: 19565236]

15. Schipperus R, Eggink G, de Wolf FA. Secretion of elastin-like polypeptides with different transition temperatures by Pichia pastoris. Biotechnol. Prog. 2012; 28:242-247. [PubMed: 22002940]

16. Herzog RW, Singh NK, Urry DW, Daniell H. Expression of a synthetic protein-based polymer (elastomer) gene in Aspergillus nidulans. Appl. Microbiol. Biotechnol. 1997; 47:368-372. [PubMed: 9163950]

17. Conley AJ, Joensuu JJ, Jevnikar AM, Menassa R, Brandle JE. Optimization of elastin-like polypeptide fusions for expression and purification of recombinant proteins in plants. Biotechnol. Bioeng. 2009; 103:562-573. [PubMed: 19266472]

18. Conrad U, Plagmann I, Malchow S, Sack M, Floss DM, Kruglov AA, Nedospasov SA, Rose-John $\mathrm{S}$, Scheller J. ELPylated anti-human TNF therapeutic single-domain antibodies for prevention of lethal septic shock. Plant Biotechnol. J. 2011; 9:22-31. [PubMed: 20444206]

19. Kaldis A, Ahmad A, Reid A, McGarvey B, Brandle J, Ma SW, Jevnikar A, Kohalmi SE, Menassa R. High-level production of human interleukin-10 fusions in tobacco cell suspension cultures. Plant Biotechnol. J. 2013; 11:535-545. [PubMed: 23297698]

20. Meyer DE, Chilkoti A. Purification of recombinant proteins by fusion with thermally-responsive polypeptides. Nat. Biotechnol. 1999; 17:1112-1115. [PubMed: 10545920]

21. Urry DW, Parker TM, Reid MC, Gowda DC. Biocompatibility of the bioelastic materials, poly(GVGVP) and its gamma-irradiation cross-linked matrix: summary of generic biological test results. J. Bioact. Compatible Polym. 1991; 6:263-282.

22. Urry DW, Pattanaik A, Xu J, Woods TC, McPherson DT, Parker TM. Elastic protein-based polymers in soft tissue augmentation and generation. J. Biomater. Sci. Polym. Ed. 1998; 9:10151048. [PubMed: 9806444]

23. Rincon AC, Molina-Martinez IT, de Las Heras B, Alonso M, Bailez C, Rodriguez-Cabello JC, Herrero-Vanrell R. Biocompatibility of elastin-like polymer poly(VPAVG) microparticles: in vitro and in vivo studies. J. Biomed. Mater. Res. A. 2006; 78:343-351. [PubMed: 16646066]

24. Christiansen M, Matson M, Brazg R, Georgopoulos L, Arnold S, Kramer W, Shi L, Strange P. Weekly subcutaneous doses of PB1023 a novel GLP-1 analogue reduce glucose exposure dose dependently. phasebio.com/wp-content/uploads/2013/12/PosterPresentation-ADAFINAL-6JUN2012-V1_Blackout-Version-17Jun20131.pdf.

25. Liu W, Dreher MR, Chow DC, Zalutsky MR, Chilkoti A. Tracking the in vivo fate of recombinant polypeptides by isotopic labeling. J. Control. Release. 2006; 114:184-192. [PubMed: 16904221]

26. Liu W, Dreher MR, Furgeson DY, Peixoto KV, Yuan H, Zalutsky MR, Chilkoti A. Tumor accumulation, degradation and pharmacokinetics of elastin-like polypeptides in nude mice. J. Control. Release. 2006; 116:170-178. [PubMed: 16919353]

27. Shah M, Hsueh PY, Sun G, Chang HY, Janib SM, MacKay JA. Biodegradation of elastin-like polypeptide nanoparticles. Protein Sci. 2012; 21:743-750. [PubMed: 22434766]

28. Floss DM, Schallau K, Rose-John S, Conrad U, Scheller J. Elastin-like polypeptides revolutionize recombinant protein expression and their biomedical application. Trends Biotechnol. 2010; 28:3745. [PubMed: 19897265] 
29. Trabbic-Carlson K, Meyer DE, Liu L, Piervincenzi R, Nath N, LaBean T, Chilkoti A. Effect of protein fusion on the transition temperature of an environmentally responsive elastin-like polypeptide: a role for surface hydrophobicity? Protein Eng. Des. Sel. 2004; 17:57-66. [PubMed: 14985538]

30. Trabbic-Carlson K, Liu L, Kim B, Chilkoti A. Expression and purification of recombinant proteins from Escherichia coli: comparison of an elastin-like polypeptide fusion with an oligohistidine fusion. Protein Sci. 2004; 13:3274-3284. [PubMed: 15557268]

31. Yang K, Su YJ, Li JH, Sun J, Yang YJ. Expression and purification of the antimicrobial peptide cecropin AD by fusion with cationic elastin-like polypeptides. Protein Expr. Purif. 2012; 85:200203. [PubMed: 22651919]

32. Lan DM, Huang GR, Shao HW, Zhang LC, Ma LX, Chen SW, Xu AL. An improved nonchromatographic method for the purification of recombinant proteins using elastin-like polypeptide-tagged proteases. Anal. Biochem. 2011; 415:200-202. [PubMed: 21600185]

33. Zhang J, Ma L, Zhang SQ. Expression and purification of soluble human APRIL in Escherichia coli using ELP-SUMO tag. Protein Expr. Purif. 2014; 95:177-181. [PubMed: 24412409]

34. Hu F, Ke T, Li X, Mao PH, Jin X, Hui FL, Ma XD, Ma LX. Expression and purification of an antimicrobial peptide by fusion with elastin-like polypeptides in Escherichia coli. Appl. Biochem. Biotechnol. 2010; 160:2377-2387. [PubMed: 19924386]

35. Banki MR, Feng L, Wood DW. Simple bioseparations using self-cleaving elastin-like polypeptide tags. Nat. Methods. 2005; 2:659-661. [PubMed: 16074986]

36. Ge X, Yang DS, Trabbic-Carlson K, Kim B, Chilkoti A, Filipe CD. Self-cleavable stimulus responsive tags for protein purification without chromatography. J. Am. Chem. Soc. 2005; 127:11228-11229. [PubMed: 16089436]

37. Shen Y, Ai HX, Song R, Liang ZN, Li JF, Zhang SQ. Expression and purification of moricin CM4 and human beta-defensins 4 in Escherichia coli using a new technology. Microbiol. Res. 2010; 165:713-718. [PubMed: 20089386]

38. Bellucci JJ, Amiram M, Bhattacharyya J, McCafferty D, Chilkoti A. Three-in-one chromatography-free purification, tag removal, and site-specific modification of recombinant fusion proteins using sortase A and elastin-like polypeptides. Angew. Chem. Int. Ed. Engl. 2013; 52:3703-3708. [PubMed: 23424160]

39. Kim DH, Smith JT, Chilkoti A, Reichert WM. The effect of covalently immobilized rhIL-1ra-ELP fusion protein on the inflammatory profile of LPS-stimulated human monocytes. Biomaterials. 2007; 28:3369-3377. [PubMed: 17482260]

40. Patel J, Zhu H, Menassa R, Gyenis L, Richman A, Brandle J. Elastin-like polypeptide fusions enhance the accumulation of recombinant proteins in tobacco leaves. Transgenic Res. 2007; 16:239-249. [PubMed: 17106768]

41. Floss DM, Sack M, Arcalis E, Stadlmann J, Quendler H, Rademacher T, Stoger E, Scheller J, Fischer R, Conrad U. Influence of elastin-like peptide fusions on the quantity and quality of a tobacco-derived human immunodeficiency virus-neutralizing antibody. Plant Biotechnol. J. 2009; 7:899-913. [PubMed: 19843249]

42. Sarangthem V, Cho EA, Bae SM, Singh TD, Kim SJ, Kim S, Jeon WB, Lee BH, Park RW. Construction and application of elastin like polypeptide containing IL-4 receptor targeting peptide. PLoS One. 2013; 8:e81891. [PubMed: 24339977]

43. Massodi I, Bidwell GL 3rd, Raucher D. Evaluation of cell penetrating peptides fused to elastin-like polypeptide for drug delivery. J. Control. Release. 2005; 108:396-408. [PubMed: 16157413]

44. Dreher MR, Raucher D, Balu N, Michael Colvin O, Ludeman SM, Chilkoti A. Evaluation of an elastin-like polypeptide-doxorubicin conjugate for cancer therapy. J. Control. Release. 2003; 91:31-43. [PubMed: 12932635]

45. Furgeson DY, Dreher MR, Chilkoti A. Structural optimization of a "smart" doxorubicinpolypeptide conjugate for thermally targeted delivery to solid tumors. J. Control. Release. 2006; 110:362-369. [PubMed: 16303202]

46. Bidwell GL 3rd, Davis AN, Fokt I, Priebe W, Raucher D. A thermally targeted elastin-like polypeptide-doxorubicin conjugate overcomes drug resistance. Invest. New Drugs. 2007; 25:313326. [PubMed: 17483874] 
47. Dreher MR, Simnick AJ, Fischer K, Smith RJ, Patel A, Schmidt M, Chilkoti A. Temperature triggered self-assembly of polypeptides into multivalent spherical micelles. J. Am. Chem. Soc. 2008; 130:687-694. [PubMed: 18085778]

48. Simnick AJ, Amiram M, Liu W, Hanna G, Dewhirst MW, Kontos CD, Chilkoti A. In vivo tumor targeting by a NGR-decorated micelle of a recombinant diblock copolypeptide. J. Control. Release. 2011; 155:144-151. [PubMed: 21763734]

49. Sun G, Hsueh PY, Janib SM, Hamm-Alvarez S, MacKay JA. Design and cellular internalization of genetically engineered polypeptide nanoparticles displaying adenovirus knob domain. J. Control. Release. 2011; 155:218-226. [PubMed: 21699930]

50. Shi P, Aluri S, Lin YA, Shah M, Edman M, Dhandhukia J, Cui H, MacKay JA. Elastin-based protein polymer nanoparticles carrying drug at both corona and core suppress tumor growth in vivo. J. Control. Release. 2013; 171:330-338. [PubMed: 23714121]

51. Shah M, Edman MC, Janga SR, Shi P, Dhandhukia J, Liu S, Louie SG, Rodgers K, Mackay JA, Hamm-Alvarez SF. A rapamycin-binding protein polymer nanoparticle shows potent therapeutic activity in suppressing autoimmune dacryoadenitis in a mouse model of Sjogren's syndrome. J. Control. Release. 2013; 171:269-279. [PubMed: 23892265]

52. MacKay JA, Chen M, McDaniel JR, Liu W, Simnick AJ, Chilkoti A. Self-assembling chimeric polypeptide-doxorubicin conjugate nanoparticles that abolish tumours after a single injection. Nat. Mater. 2009; 8:993-999. [PubMed: 19898461]

53. McDaniel JR, Bhattacharyya J, Vargo KB, Hassouneh W, Hammer DA, Chilkoti A. Self-assembly of thermally responsive nanoparticles of a genetically encoded peptide polymer by drug conjugation. Angew. Chem. Int. Ed. Engl. 2013; 52:1683-1687. [PubMed: 23280697]

54. Chen TH, Bae Y, Furgeson DY. Intelligent biosynthetic nanobiomaterials (IBNs) for hyperthermic gene delivery. Pharm. Res. 2008; 25:683-691. [PubMed: 17762916]

55. Bessa PC, Machado R, Nurnberger S, Dopler D, Banerjee A, Cunha AM, Rodriguez-Cabello JC, Redl H, van Griensven M, Reis RL, Casal M. Thermoresponsive self-assembled elastin-based nanoparticles for delivery of BMPs. J. Control. Release. 2010; 142:312-318. [PubMed: 19913578]

56. Koria P, Yagi H, Kitagawa Y, Megeed Z, Nahmias Y, Sheridan R, Yarmush ML. Self-assembling elastin-like peptides growth factor chimeric nanoparticles for the treatment of chronic wounds. Proc. Natl. Acad. Sci. U. S. A. 2011; 108:1034-1039. [PubMed: 21193639]

57. Na K, Jung J, Lee J, Hyun J. Thermoresponsive pore structure of biopolymer microspheres for a smart drug carrier. Langmuir. 2010; 26:11165-11169. [PubMed: 20550167]

58. Cheng J, Park M, Lim DW, Hyun J. Polypeptide microgel capsules as drug carriers. Macromolecular Research. 2013; 21:1163-1166.

59. Dash BC, Mahor S, Carroll O, Mathew A, Wang W, Woodhouse KA, Pandit A. Tunable elastinlike polypeptide hollow sphere as a high payload and controlled delivery gene depot. J. Control. Release. 2011; 152:382-392. [PubMed: 21397644]

60. Lee TAT, Cooper A, Apkarian RP, Conticello VP. Thermo-reversible self-assembly of nanoparticles derived from elastin-mimetic polypeptides. Adv. Mater. 2000; 12:1105-1110.

61. Janib SM, Pastuszka M, Aluri S, Folchman-Wagner Z, Hsueh PY, Shi P, Yi A, Cui H, Mackay JA. A quantitative recipe for engineering protein polymer nanoparticles. Polym. Chem. 2014; 5:16141625. [PubMed: 24511327]

62. Kim W, Thevenot J, Ibarboure E, Lecommandoux S, Chaikof EL. Self-assembly of thermally responsive amphiphilic diblock copolypeptides into spherical micellar nanoparticles. Angew. Chem. Int. Ed. Engl. 2010; 49:4257-4260. [PubMed: 20446331]

63. Lim DW, Trabbic-Carlson K, Mackay JA, Chilkoti A. Improved non-chromatographic purification of a recombinant protein by cationic elastin-like polypeptides. Biomacromolecules. 2007; 8:14171424. [PubMed: 17407348]

64. Trabbic-Carlson K, Setton LA, Chilkoti A. Swelling and mechanical behaviors of chemically cross-linked hydrogels of elastin-like polypeptides. Biomacromolecules. 2003; 4:572-580. [PubMed: 12741772]

65. Herrero-Vanrell R, Rincon AC, Alonso M, Reboto V, Molina-Martinez IT, Rodriguez-Cabello JC. Self-assembled particles of an elastin-like polymer as vehicles for controlled drug release. J. Control. Release. 2005; 102:113-122. [PubMed: 15653138] 
66. Nagapudi K, Brinkman WT, Leisen JE, Huang L, McMillan RA, Apkarian RP, Conticello VP, Chaikof EL. Photomediated solid-state cross-linking of an elastin-mimetic recombinant protein polymer. Macromolecules. 2002; 35:1730-1737.

67. Martinez AW, Caves JM, Ravi S, Li W, Chaikof EL. Effects of crosslinking on the mechanical properties, drug release and cytocompatibility of protein polymers. Acta Biomater. 2014; 10:2633. [PubMed: 23993944]

68. McHale MK, Setton LA, Chilkoti A. Synthesis and in vitro evaluation of enzymatically crosslinked elastin-like polypeptide gels for cartilaginous tissue repair. Tissue Eng. 2005; 11:17681779. [PubMed: 16411822]

69. Lim DW, Nettles DL, Setton LA, Chilkoti A. In situ cross-linking of elastin-like polypeptide block copolymers for tissue repair. Biomacromolecules. 2008; 9:222-230. [PubMed: 18163573]

70. Falk MH, Issels RD. Hyperthermia in oncology. Int. J. Hyperthermia. 2001; 17:1-18. [PubMed: 11212876]

71. Jones E, Thrall D, Dewhirst MW, Vujaskovic Z. Prospective thermal dosimetry: the key to hyperthermia's future. Int. J. Hyperthermia. 2006; 22:247-253. [PubMed: 16754346]

72. Wu L, McGough RJ, Arabe OA, Samulski TV. An RF phased array applicator designed for hyperthermia breast cancer treatments. Phys. Med. Biol. 2006; 51:1-20. [PubMed: 16357427]

73. Partanen A, Yarmolenko PS, Viitala A, Appanaboyina S, Haemmerich D, Ranjan A, Jacobs G, Woods D, Enholm J, Wood BJ, Dreher MR. Mild hyperthermia with magnetic resonance-guided high-intensity focused ultrasound for applications in drug delivery. Int. J. Hyperthermia. 2012; 28:320-336. [PubMed: 22621734]

74. Meyer DE, Kong GA, Dewhirst MW, Zalutsky MR, Chilkoti A. Targeting a genetically engineered elastin-like polypeptide to solid tumors by local hyperthermia. Cancer Res. 2001; 61:1548-1554. [PubMed: 11245464]

75. Meyer DE, Shin BC, Kong GA, Dewhirst MW, Chilkoti A. Drug targeting using thermally responsive polymers and local hyperthermia. J. Control. Release. 2001; 74:213-224. [PubMed: 11489497]

76. Dreher MR, Liu W, Michelich CR, Dewhirst MW, Chilkoti A. Thermal cycling enhances the accumulation of a temperature-sensitive biopolymer in solid tumors. Cancer Res. 2007; 67:44184424. [PubMed: 17483356]

77. Raucher D, Chilkoti A. Enhanced uptake of a thermally responsive polypeptide by tumor cells in response to its hyperthermia-mediated phase transition. Cancer Res. 2001; 61:7163-7170. [PubMed: 11585750]

78. Na K, Lee SA, Jung SH, Hyun J, Shin BC. Elastin-like polypeptide modified liposomes for enhancing cellular uptake into tumor cells. Colloids Surf. B Biointerfaces. 2012; 91:130-136. [PubMed: 22104404]

79. Bidwell GL 3rd, Raucher D. Application of thermally responsive polypeptides directed against cMyc transcriptional function for cancer therapy. Mol. Cancer Ther. 2005; 4:1076-1085. [PubMed: 16020665]

80. Bidwell GL 3rd, Davis AN, Raucher D. Targeting a c-Myc inhibitory polypeptide to specific intracellular compartments using cell penetrating peptides. J. Control. Release. 2009; 135:2-10. [PubMed: 19095020]

81. Massodi I, Moktan S, Rawat A, Bidwell GL 3rd, Raucher D. Inhibition of ovarian cancer cell proliferation by a cell cycle inhibitory peptide fused to a thermally responsive polypeptide carrier. Int. J. Cancer. 2010; 126:533-544. [PubMed: 19588502]

82. Massodi I, Thomas E, Raucher D. Application of thermally responsive elastin-like polypeptide fused to a lactoferrin-derived peptide for treatment of pancreatic cancer. Molecules. 2009; 14:1999-2015. [PubMed: 19513001]

83. Bidwell GL 3rd, Whittom AA, Thomas E, Lyons D, Hebert MD, Raucher D. A thermally targeted peptide inhibitor of symmetrical dimethylation inhibits cancer-cell proliferation. Peptides. 2010; 31:834-841. [PubMed: 20167239]

84. Massodi I, Raucher D. A thermally responsive Tat-elastin-like polypeptide fusion protein induces membrane leakage, apoptosis, and cell death in human breast cancer cells. J. Drug Target. 2007; 15:611-622. [PubMed: 17968715] 
85. Bidwell GL 3rd, Perkins E, Raucher D. A thermally targeted c-Myc inhibitory polypeptide inhibits breast tumor growth. Cancer Lett. 2012; 319:136-143. [PubMed: 22261328]

86. Bidwell GL 3rd, Perkins E, Hughes J, Khan M, James JR, Raucher D. Thermally targeted delivery of a c-Myc inhibitory polypeptide inhibits tumor progression and extends survival in a rat glioma model. PLoS One. 2013; 8:e55104. [PubMed: 23372821]

87. Bidwell GL 3rd, Fokt I, Priebe W, Raucher D. Development of elastin-like polypeptide for thermally targeted delivery of doxorubicin. Biochem. Pharmacol. 2007; 73:620-631. [PubMed: 17161827]

88. Moktan S, Ryppa C, Kratz F, Raucher D. A thermally responsive biopolymer conjugated to an acid-sensitive derivative of paclitaxel stabilizes microtubules, arrests cell cycle, and induces apoptosis. Invest. New Drugs. 2012; 30:236-248. [PubMed: 20938714]

89. Walker L, Perkins E, Kratz F, Raucher D. Cell penetrating peptides fused to a thermally targeted biopolymer drug carrier improve the delivery and antitumor efficacy of an acidsensitive doxorubicin derivative. Int. J. Pharm. 2012; 436:825-832. [PubMed: 22850291]

90. Moktan S, Perkins E, Kratz F, Raucher D. Thermal targeting of an acid-sensitive doxorubicin conjugate of elastin-like polypeptide enhances the therapeutic efficacy compared with the parent compound in vivo. Mol. Cancer Ther. 2012; 11:1547-1556. [PubMed: 22532601]

91. Simnick AJ, Valencia CA, Liu R, Chilkoti A. Morphing low-affinity ligands into highavidity nanoparticles by thermally triggered self-assembly of a genetically encoded polymer. ACS nano. 2010; 4:2217-2227. [PubMed: 20334355]

92. Hassouneh W, Fischer K, MacEwan SR, Branscheid R, Fu CL, Liu R, Schmidt M, Chilkoti A. Unexpected multivalent display of proteins by temperature triggered self-assembly of elastin-like polypeptide block copolymers. Biomacromolecules. 2012; 13:1598-1605. [PubMed: 22515311]

93. MacEwan SR, Chilkoti A. Digital switching of local arginine density in a genetically encoded selfassembled polypeptide nanoparticle controls cellular uptake. Nano Lett. 2012; 12:3322-3328. [PubMed: 22625178]

94. MacEwan SR, Chilkoti A. Controlled apoptosis by a thermally toggled nanoscale amplifier of cellular uptake. Nano Lett. 2014; 14:2058-2064. [PubMed: 24611762]

95. McDaniel JR, MacEwan SR, Dewhirst M, Chilkoti A. Doxorubicin-conjugated chimeric polypeptide nanoparticles that respond to mild hyperthermia. J. Control. Release. 2012; 159:362367. [PubMed: 22421424]

96. McDaniel JR, MacEwan SR, Li X, Radford DC, Landon CD, Dewhirst M, Chilkoti A. Rational design of "heat seeking" drug loaded polypeptide nanoparticles that thermally target solid tumors. Nano Lett. 2014; 14:2890-2895. [PubMed: 24738626]

97. Liu W, MacKay JA, Dreher MR, Chen M, McDaniel JR, Simnick AJ, Callahan DJ, Zalutsky MR, Chilkoti A. Injectable intratumoral depot of thermally responsive polypeptide-radionuclide conjugates delays tumor progression in a mouse model. J. Control. Release. 2010; 144:2-9. [PubMed: 20117157]

98. Liu W, McDaniel J, Li X, Asai D, Quiroz FG, Schaal J, Park JS, Zalutsky M, Chilkoti A. Brachytherapy using injectable seeds that are self-assembled from genetically encoded polypeptides in situ. Cancer Res. 2012; 72:5956-5965. [PubMed: 23155121]

99. Asai D, Xu D, Liu W, Garcia Quiroz F, Callahan DJ, Zalutsky MR, Craig SL, Chilkoti A. Protein polymer hydrogels by in situ, rapid and reversible self-gelation. Biomaterials. 2012; 33:54515458. [PubMed: 22538198]

100. Betre H, Liu W, Zalutsky MR, Chilkoti A, Kraus VB, Setton LA. A thermally responsive biopolymer for intra-articular drug delivery. J. Control. Release. 2006; 115:175-182. [PubMed: 16959360]

101. Shamji MF, Betre H, Kraus VB, Chen J, Chilkoti A, Pichika R, Masuda K, Setton LA. Development and characterization of a fusion protein between thermally responsive elastin-like polypeptide and interleukin-1 receptor antagonist: sustained release of a local antiinflammatory therapeutic. Arthritis Rheum. 2007; 56:3650-3661. [PubMed: 17968946]

102. Adams SB Jr, Shamji MF, Nettles DL, Hwang P, Setton LA. Sustained release of antibiotics from injectable and thermally responsive polypeptide depots. J. Biomed. Mater. Res. B Appl.

Biomater. 2009; 90:67-74. [PubMed: 18988275] 
103. Shamji MF, Whitlatch L, Friedman AH, Richardson WJ, Chilkoti A, Setton LA. An injectable and in situ-gelling biopolymer for sustained drug release following perineural administration. Spine. 2008; 33:748-754. [PubMed: 18379401]

104. Shamji MF, Chen J, Friedman AH, Richardson WJ, Chilkoti A, Setton LA. Synthesis and characterization of a thermally-responsive tumor necrosis factor antagonist. J. Control. Release. 2008; 129:179-186. [PubMed: 18547669]

105. Shamji MF, Jing L, Chen J, Hwang P, Ghodsizadeh O, Friedman AH, Richardson WJ, Setton LA. Treatment of neuroinflammation by soluble tumor necrosis factor receptor Type II fused to a thermally responsive carrier. Journal of neurosurgery. Spine. 2008; 9:221-228. [PubMed: 18764758]

106. Sinclair SM, Bhattacharyya J, McDaniel JR, Gooden DM, Gopalaswamy R, Chilkoti A, Setton LA. A genetically engineered thermally responsive sustained release curcumin depot to treat neuroinflammation. J. Control. Release. 2013; 171:38-47. [PubMed: 23830979]

107. Amiram M, Luginbuhl KM, Li X, Feinglos MN, Chilkoti A. A depot-forming glucagon-like peptide-1 fusion protein reduces blood glucose for five days with a single injection. J. Control. Release. 2013; 172:144-151. [PubMed: 23928357]

108. Amiram M, Luginbuhl KM, Li X, Feinglos MN, Chilkoti A. Injectable protease-operated depots of glucagon-like peptide-1 provide extended and tunable glucose control. Proc. Natl. Acad. Sci. U. S. A. 2013; 110:2792-2797. [PubMed: 23359691]

109. Nath N, Chilkoti A. Interfacial phase transition of an environmentally responsive elastin biopolymer adsorbed on functionalized gold nanoparticles studied by colloidal surface plasmon resonance. J. Am. Chem. Soc. 2001; 123:8197-8202. [PubMed: 11516269]

110. Nath N, Chilkoti A. Creating "smart" surfaces using stimuli responsive polymers. Adv. Mater. 2002; 14:1243-1247.

111. Huang HC, Koria P, Parker SM, Selby L, Megeed Z, Rege K. Optically responsive gold nanorodpolypeptide assemblies. Langmuir. 2008; 24:14139-14144. [PubMed: 19360961]

112. Huang HC, Yang Y, Nanda A, Koria P, Rege K. Synergistic administration of photothermal therapy and chemotherapy to cancer cells using polypeptide-based degradable plasmonic matrices. Nanomedicine (Lond). 2011; 6:459-473. [PubMed: 21542685]

113. Park SM, Kim MS, Park SJ, Park ES, Choi KS, Kim YS, Kim HR. Novel temperature-triggered liposome with high stability: formulation, in vitro evaluation, and in vivo study combined with high-intensity focused ultrasound (HIFU). J. Control. Release. 2013; 170:373-379. [PubMed: 23770213]

114. Kim MS, Lee DW, Park K, Park SJ, Choi EJ, Park ES, Kim HR. Temperature-triggered tumorspecific delivery of anticancer agents by cRGD-conjugated thermosensitive liposomes. Colloids Surf. B Biointerfaces. 2014; 116C:17-25. [PubMed: 24441178]

115. Kojima C, Irie K. Synthesis of temperature-dependent elastin-like peptide-modified dendrimer for drug delivery. Biopolymers. 2013; 100:714-721. [PubMed: 23893507]

116. Koga T, Iimura M, Higashi N. Novel peptide-shelled dendrimer with dramatically changeable thermo-responsive character. Macromol. Biosci. 2012; 12:1043-1047. [PubMed: 22344970]

117. Kim W, George A, Evans M, Conticello VP. Cotranslational incorporation of a structurally diverse series of proline analogues in an Escherichia coli expression system. ChemBioChem. 2004; 5:928-936. [PubMed: 15239049]

118. van Hest JC, Tirrell DA. Protein-based materials, toward a new level of structural control. Chem Commun (Camb). 2001:1897-1904. [PubMed: 12240211]

119. Xie J, Schultz PG. A chemical toolkit for proteins--an expanded genetic code. Nature reviews. Molecular cell biology. 2006; 7:775-782.

120. Martin L, Castro E, Ribeiro A, Alonso M, Rodriguez-Cabello JC. Temperature-triggered selfassembly of elastin-like block co-recombinamers:the controlled formation of micelles and vesicles in an aqueous medium. Biomacromolecules. 2012; 13:293-298. [PubMed: 22263638]

121. Aluri S, Pastuszka MK, Moses AS, MacKay JA. Elastin-like peptide amphiphiles form nanofibers with tunable length. Biomacromolecules. 2012; 13:2645-2654. [PubMed: 22849577] 
122. Aluri SR, Shi P, Gustafson JA, Wang W, Lin YA, Cui H, Liu S, Conti PS, Li Z, Hu P, Epstein AL, MacKay JA. A hybrid protein-polymer nanoworm potentiates apoptosis better than a monoclonal antibody. ACS nano. 2014; 8:2064-2076. [PubMed: 24484356] 

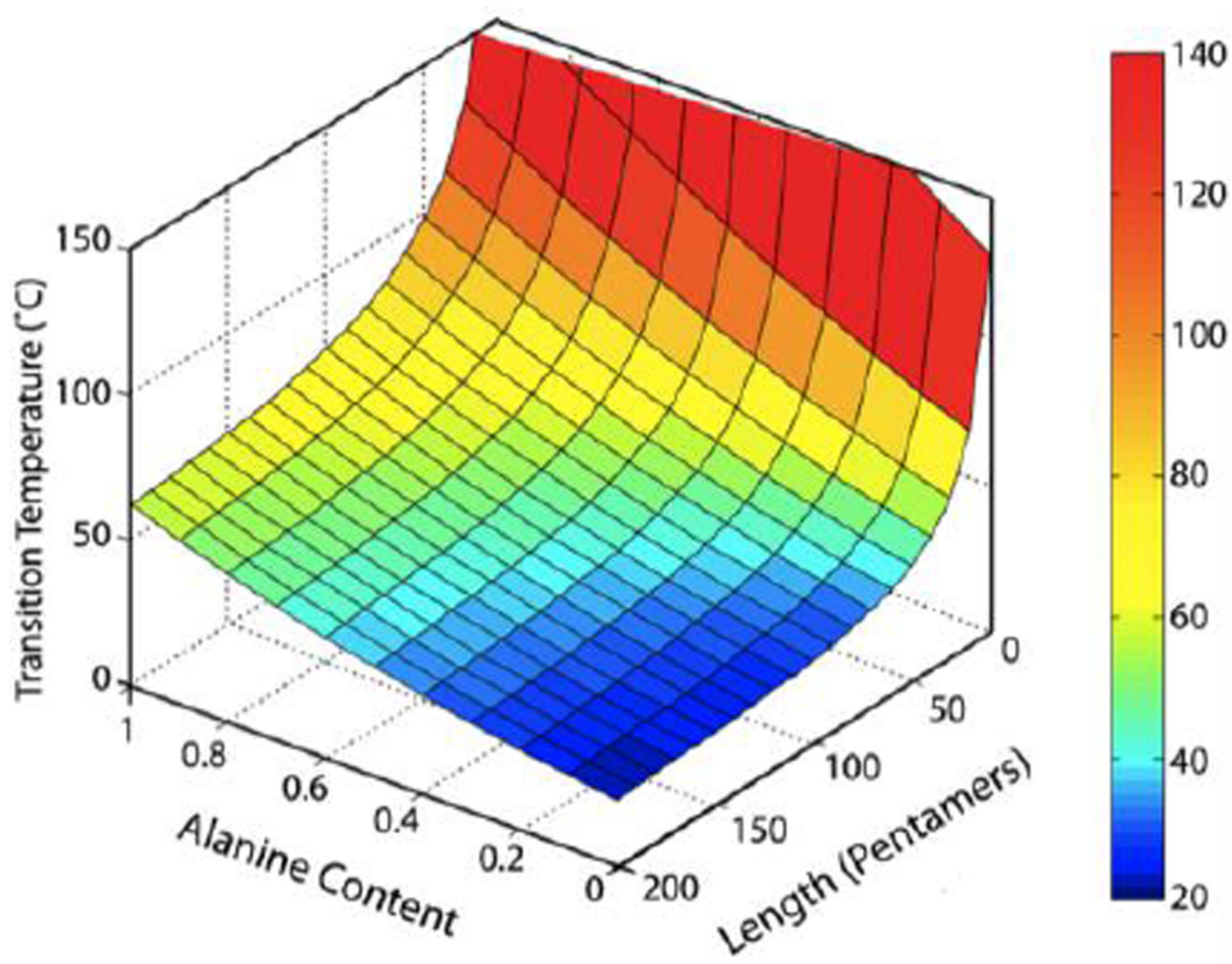

Figure 1.

Intrinsic design parameters of ELP length and guest residue composition (alanine guest residue titration into a $100 \%$ valine guest residue sequence) provided precise control of the $\mathrm{T}_{\mathrm{t}}$. Quantitative modeling of $(\mathrm{VPGXG})_{\mathrm{n}}$, with variables $\mathrm{X}=$ guest residue of alanine and valine (expressed as fraction of alanine content) and $\mathrm{n}=$ chain length inpentapeptides, allowed prediction of the $\mathrm{T}_{\mathrm{t}}$ over a broad temperature range for ELPs at $25 \mu \mathrm{M}$ in PBS. Adapted with permission from [3]. Copyright 2013 American Chemical Society. 


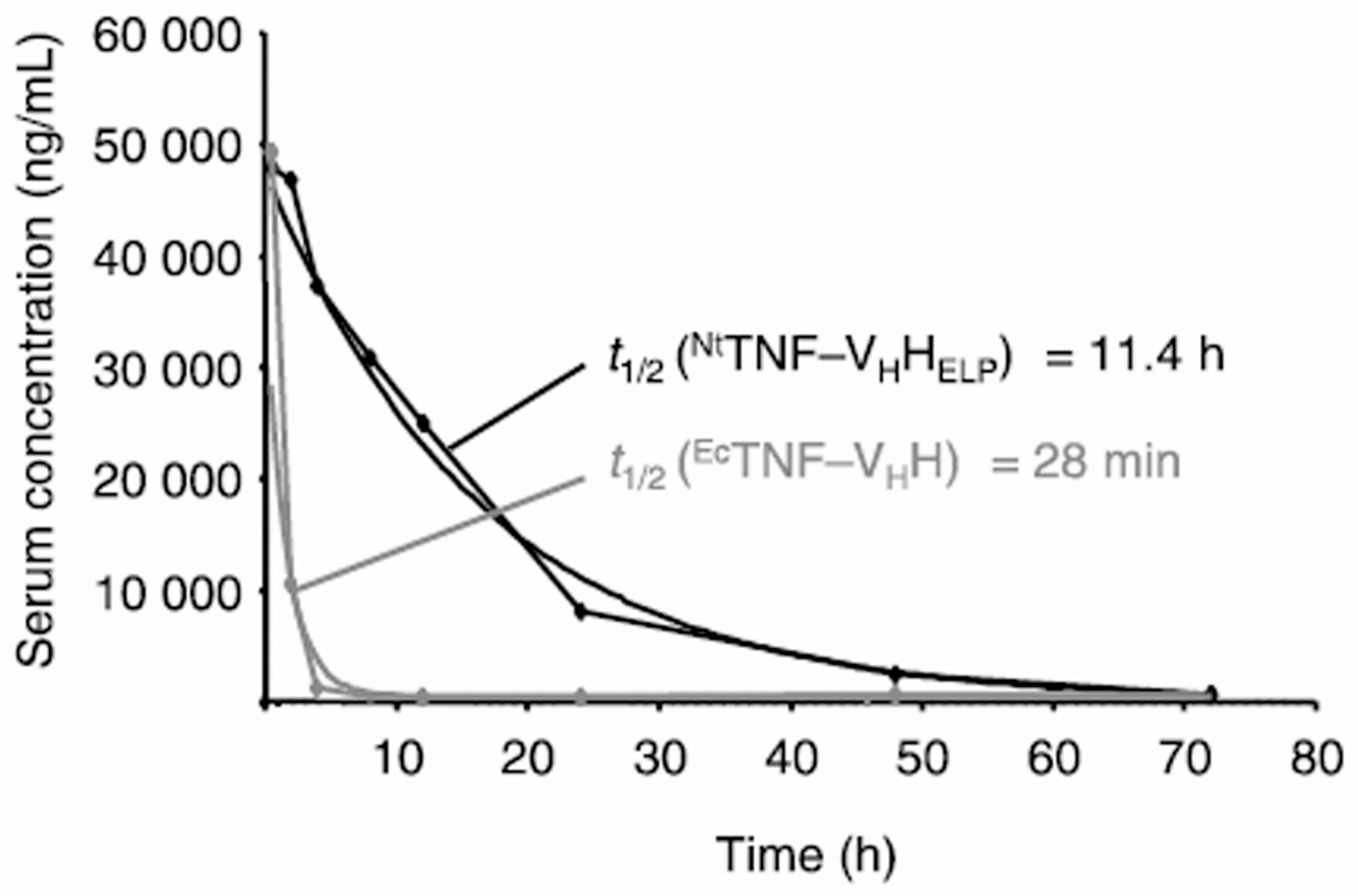

Figure 2.

ELP unimers confer improved pharmacokinetics to therapeutic protein fusions. Anti-TNF antibody fused to an ELP unimer expressed in Nicotiana tabacum $\left({ }^{\mathrm{NT}} \mathrm{TNF}-\mathrm{V}_{\mathrm{H}} \mathrm{H}_{\mathrm{ELP}}\right)$ exhibited increased serum half-life $\left(\mathrm{t}_{1 / 2}\right)$ as compared to free anti-TNF antibody expressed in E. coli $\left({ }^{\mathrm{Ec}} \mathrm{TNF}-\mathrm{V}_{\mathrm{H}} \mathrm{H}\right)$ following intravenous injection in mice. Adapted from [18]. Copyright 2011 John Wiley \& Sons. 

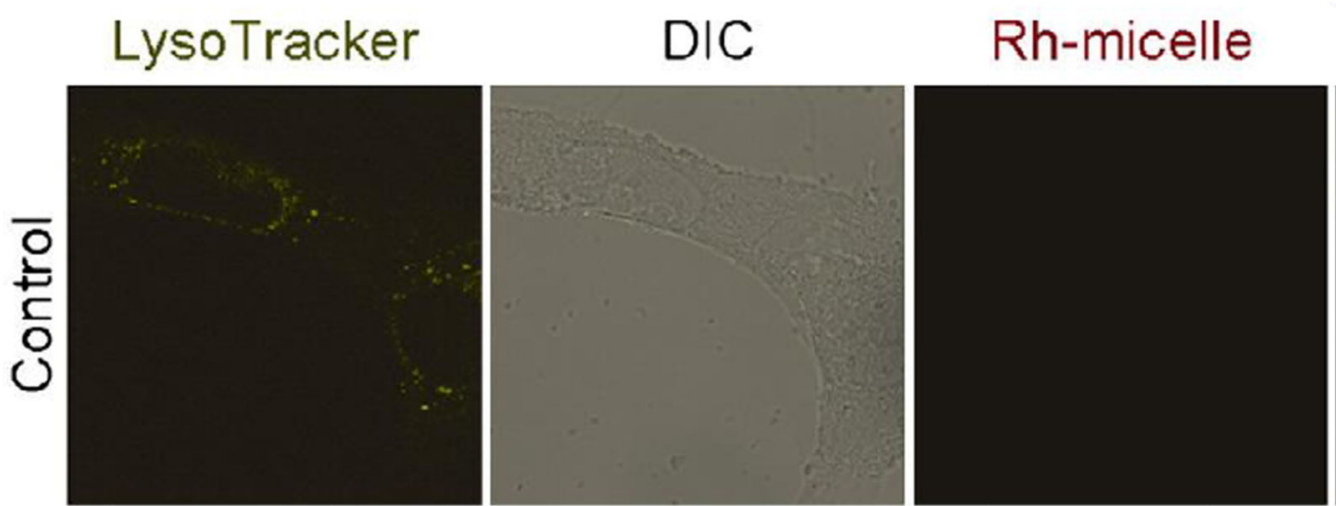

LysoTracker and
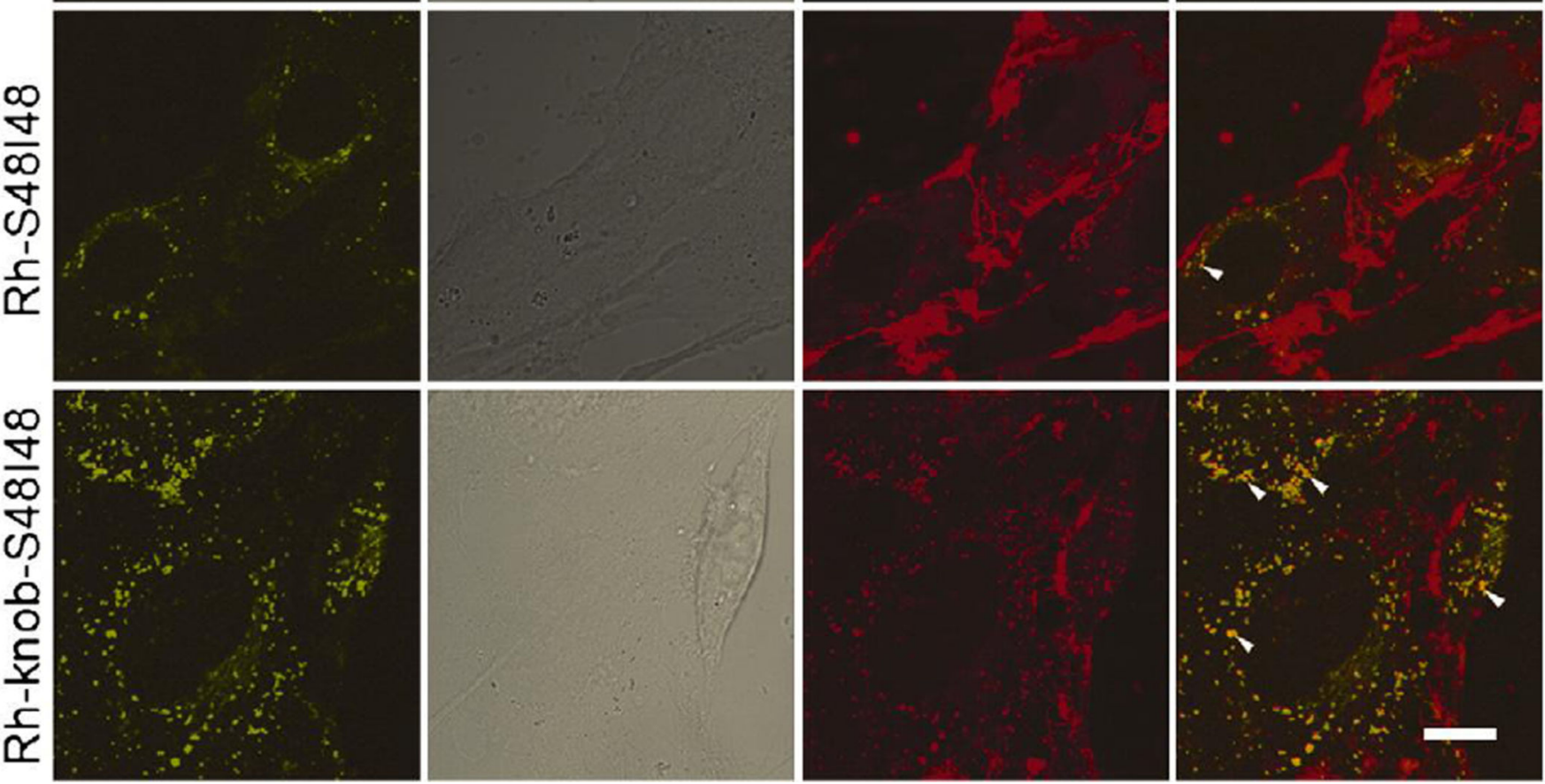

Figure 3 .

Knob-functionalized ELPBCs exhibited enhanced cellular uptake in CAR-expressing hepatocytes after 30 min incubation. Rhodamine-labeled block copolymers (Rh-S48I48) demonstrated significant localization at the cellular membrane, while rhodamine-labeled knob-functionalized block copolymers (Rh-knob-S48I48) demonstrated enhanced intracellular localization. Further evidence of enhanced cellular uptake was apparent in the colocalization of knob-functionalized ELPBC and a lysosomal marker. Green-LysoTracker; Red-ELP ${ }_{B C}$; Scale bars $10 \mu \mathrm{m}$. Reprinted from [49], Copyright 2011, with permission from Elsevier. 

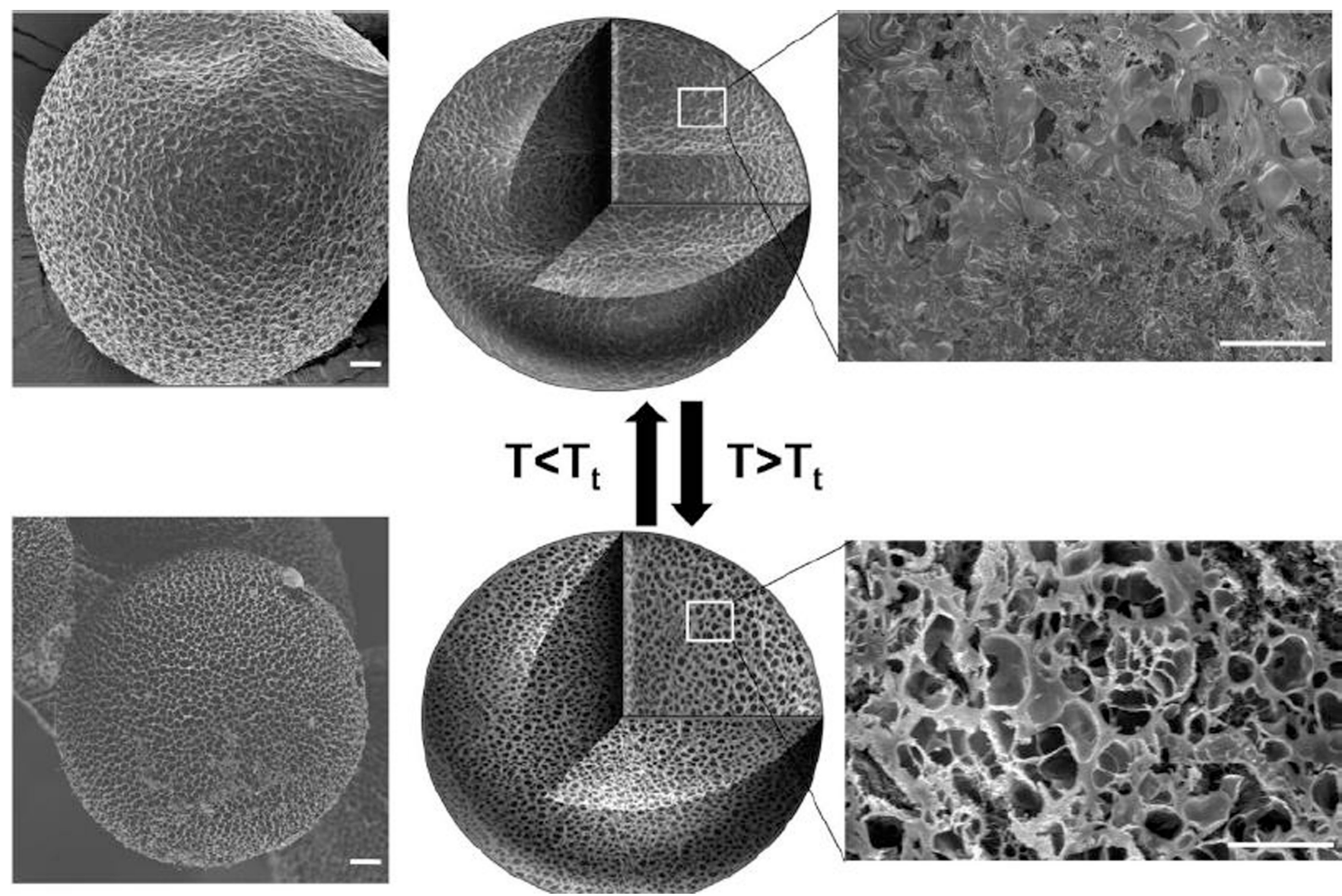

Figure 4.

Microparticles composed of glutaraldehyde-cross-linked ELP and albumin mixtures at a ratio of 3:1 exhibited temperature-induced changes in volume and porosity, evident both on the particle surface (left) and particle interior (right), as observed with field-emission scanning electron microscopy. Scale bars $20 \mu \mathrm{m}$. Reprinted with permission from [57]. Copyright 2010 American Chemical Society. 


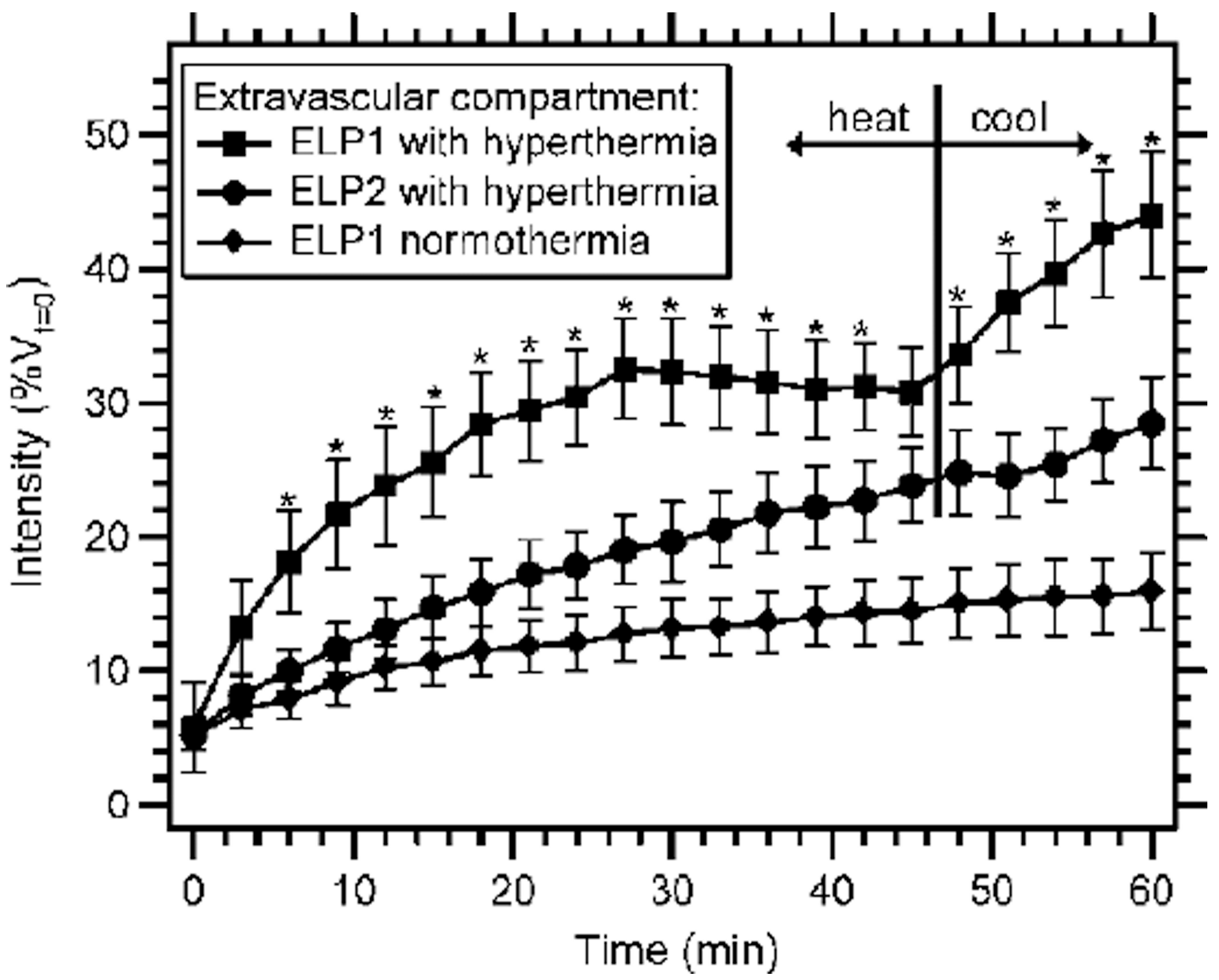

Figure 5.

Local aggregation of fluorophore-labeled temperature-sensitive ELP (ELP1) in hyperthermia-treated tumors increased accumulation (measured by fluorescence intensity of the extravascular compartment) over the course of heating, as compared to temperatureinsensitive ELP (ELP2) with tumor hyperthermia or temperaturesensitive ELP without heat. Upon tumor cooling, resolubilization of local aggregates increased the accumulation of temperature-sensitive ELP in the extravascular space. Reprinted from [76]. Copyright 2007 American Association for Cancer Research. 


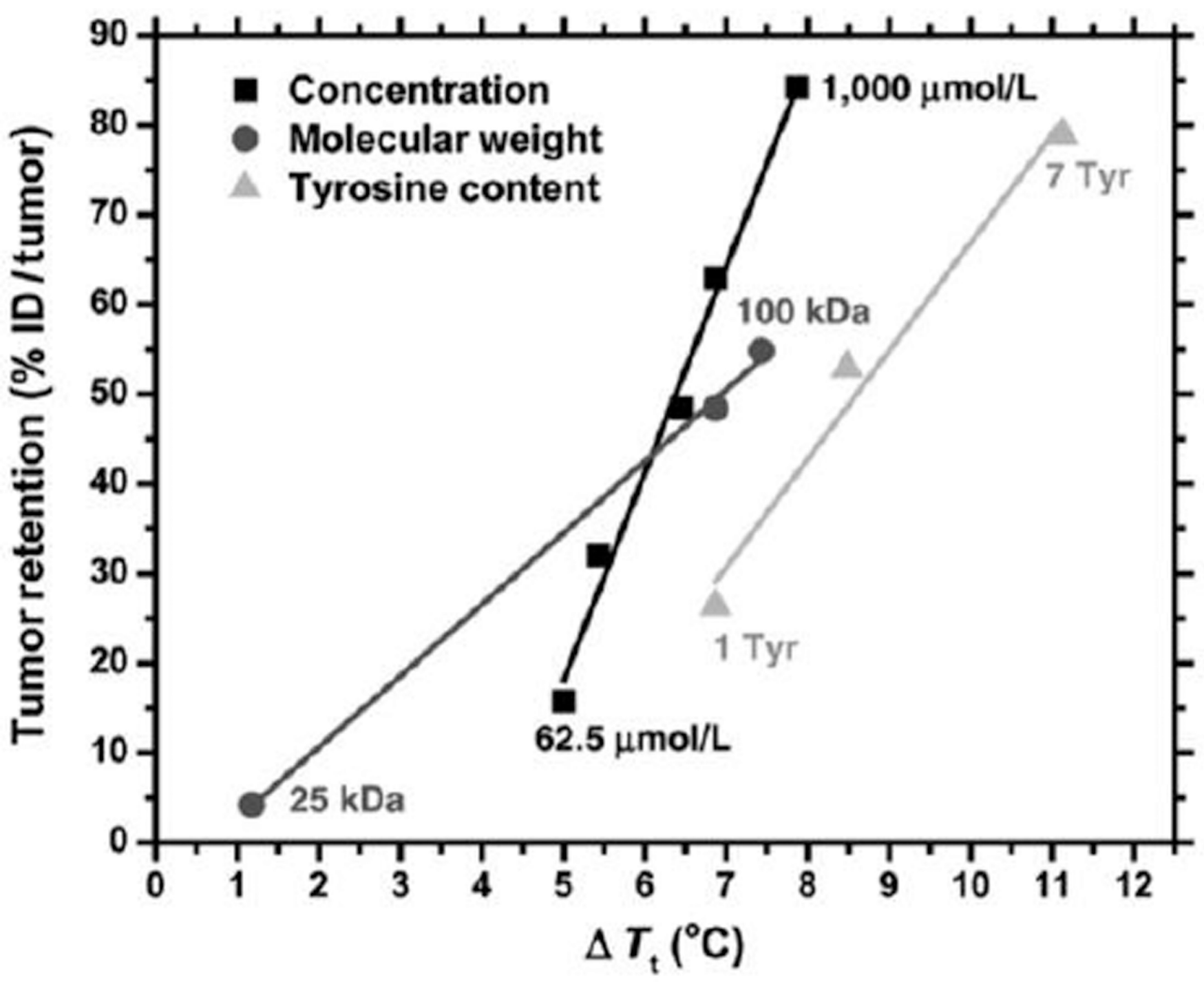

Figure 6.

Parameters of ELP depot design influence the tumor retention by their effect on the ELP Tt. The tumor retention of various 125I-labeled ELP depots 7 days after intratumoral injection was reported in relation to $\Delta \mathrm{Tt}$, the difference between $\mathrm{Tt}$ of the depot-forming ELP and the subcutaneous temperature of the tumor $\left(\sim 31.7^{\circ} \mathrm{C}\right.$ in anesthetized mice). Adapted from [98]. Copyright 2012 American Association for Cancer Research. 

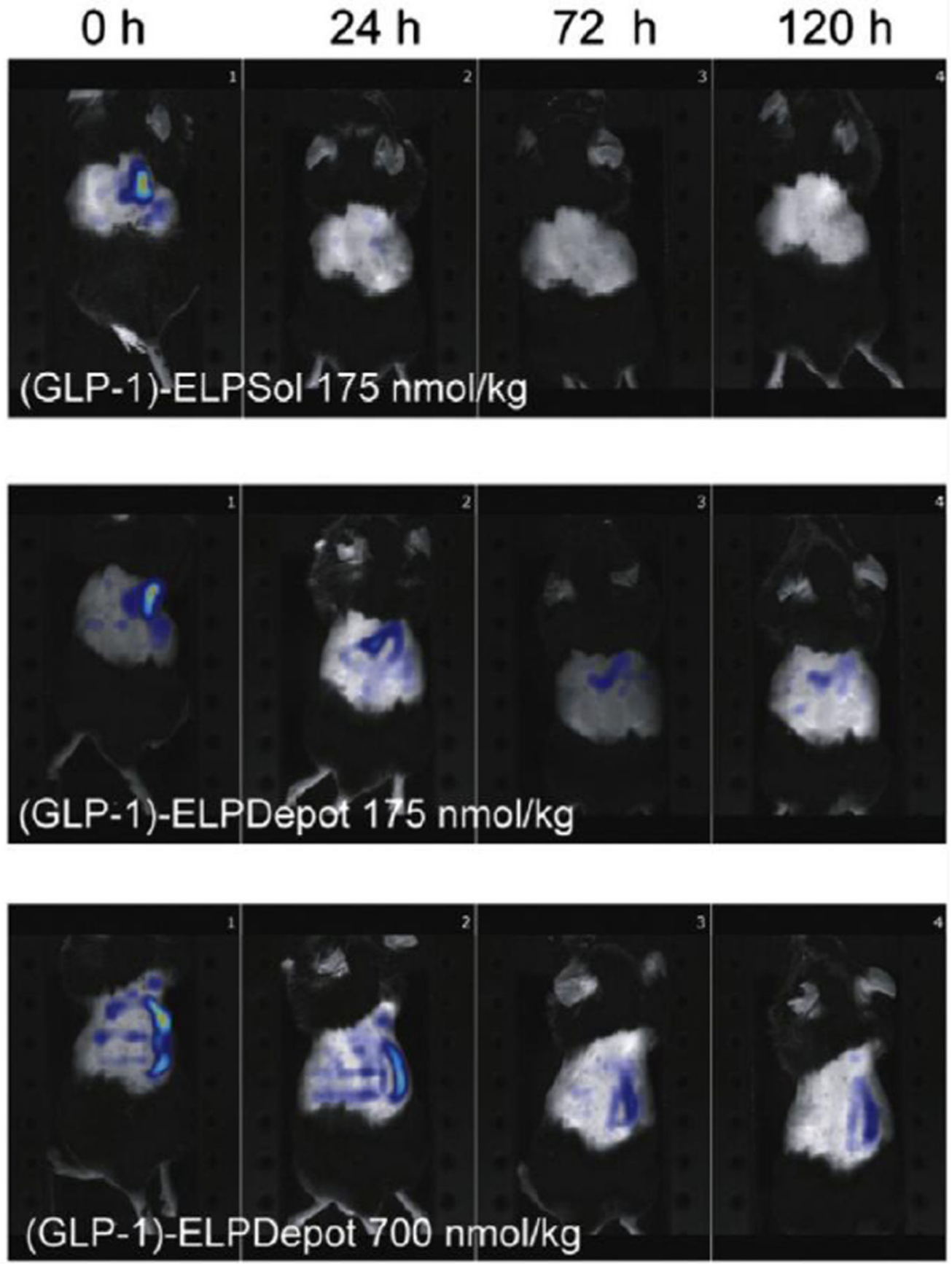

Figure 7.

Depot-forming GLP-1 ELP fusions ((GLP-1)-ELPDepot $175 \mathrm{nmol} / \mathrm{kg}$ or $700 \mathrm{nmol} / \mathrm{kg}$ ) demonstrated prolonged presence at the subcutaneous site of injection over 120 hours, as compared to a soluble GLP-1 ELP fusion control ((GLP-1)-ELPSol $175 \mathrm{nmol} / \mathrm{kg})$. High concentration GLP-1-ELPDepot at $700 \mathrm{nmol} / \mathrm{kg}$ was capable of prolonged reduction in fed glucose levels over 5 days. Adapted from [107], Copyright 2013, with permission from Elsevier. 


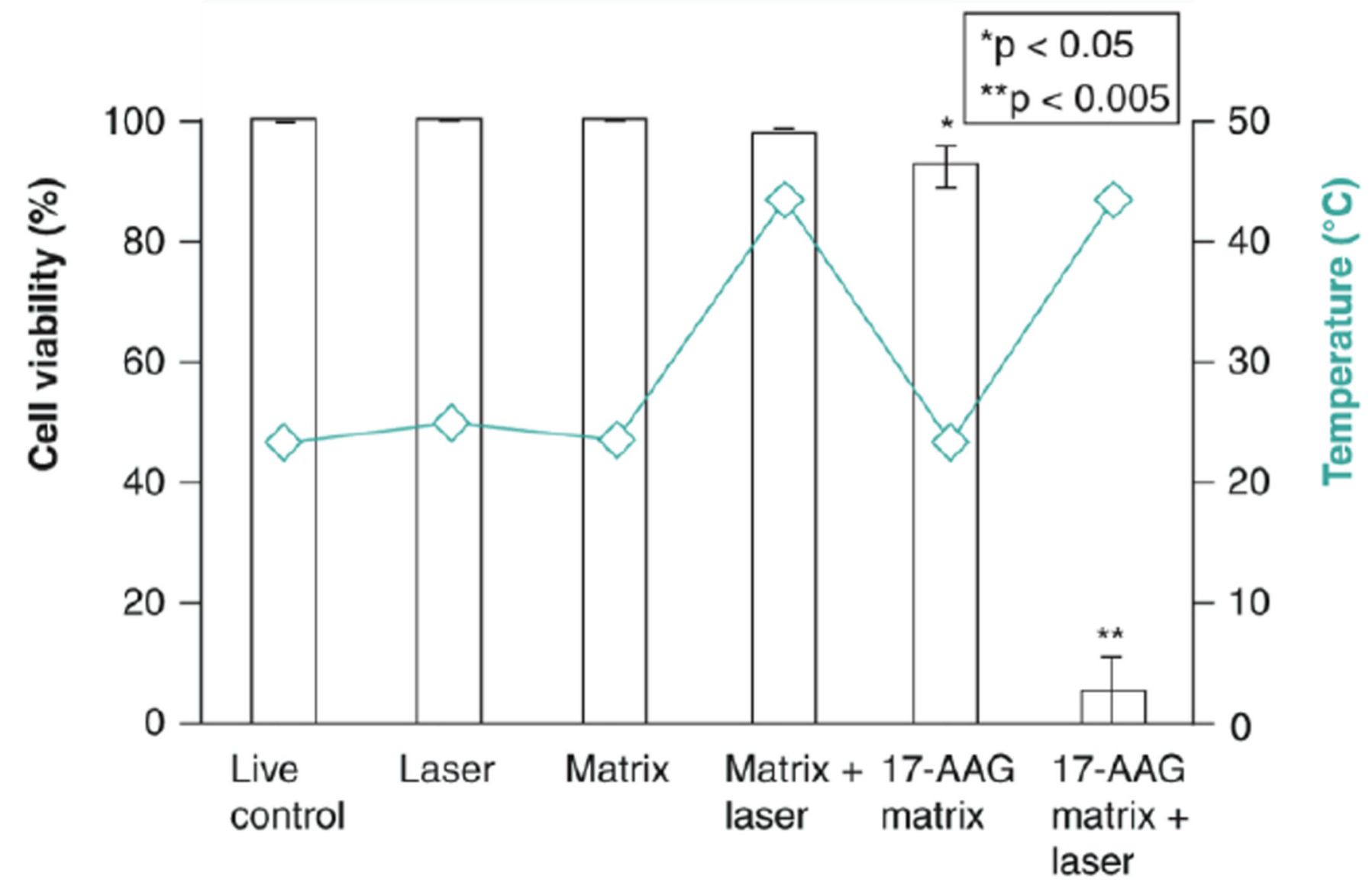

Figure 8.

ELP-functionalized gold nanorods formed composite matrices after incubation at temperatures above the ELP $\mathrm{T}_{\mathrm{t}}$. Near-infrared laser illumination induced hyperthermia by gold nanorod plasmon resonance, which in turn induced temperature-triggered release of 17AAG drug mediated by ELP aggregation, resulting in significantly enhanced cell death as compared to either hyperthermia or drug treatment alone. Adapted from [112] with permission of Future Medicine Ltd, Copyright 2011. 


\section{Table 1}

Architectures and assemblies of ELP drug carriers

\begin{tabular}{|c|c|c|c|}
\hline Application & ELP sequence & Pertinent functionalization & Ref \\
\hline \multirow{5}{*}{ Recombinant protein purification } & $(\mathrm{VPGXG})_{36} \mathrm{X}=\mathrm{K}_{1} \mathrm{~V}_{7} \mathrm{~F}_{1}$ & $\begin{array}{l}\text { Cecropin AD antimicrobial } \\
\text { peptide with enterokinase } \\
\text { cleavage site }\end{array}$ & [31] \\
\hline & $(\mathrm{VPGXG})_{90} \mathrm{X}=\mathrm{V}_{5} \mathrm{~A}_{2} \mathrm{G}_{3}$ & $\begin{array}{l}\text { Halocidin } 18 \text { antimicrobial peptide } \\
\text { with hydroxylamine cleavage site }\end{array}$ & [34] \\
\hline & $(\mathrm{VPGXG})_{110} \mathrm{X}=\mathrm{V}_{5} \mathrm{~A}_{2} \mathrm{G}_{3}$ & $\begin{array}{l}\text { Moricin CM4 and human } \beta \text { - } \\
\text { defensin } 4 \text { antimicrobial peptides } \\
\text { with intein cleavage sites }\end{array}$ & [37] \\
\hline & $(\mathrm{VPGVG})_{240}$ & $\begin{array}{l}\text { SrtA transpeptidase for site- } \\
\text { specific cleavage and triglycine } \\
\text { addition }\end{array}$ & \multirow{2}{*}{ [38] } \\
\hline & $(\mathrm{VPGXG})_{90} \mathrm{X}=\mathrm{A}_{2} \mathrm{G}_{3} \mathrm{~V}_{5}$ & $\begin{array}{l}\text { TNFa and TRAIL apoptosis- } \\
\text { inducing cytokines with SrtA } \\
\text { cleavage sites }\end{array}$ & \\
\hline \multirow{5}{*}{ Therapeutic protein ELP fusions } & $(\mathrm{VPGXG})_{90} \mathrm{X}=\mathrm{V}_{5} \mathrm{G}_{3} \mathrm{~A}_{2}$ & IL-1ra anti-inflammatory cytokine & [39] \\
\hline & $(\mathrm{VPGVG})_{27}$ & $\begin{array}{l}\text { IL-4 and IL-10 anti-inflammatory } \\
\text { cytokines }\end{array}$ & {$[19,40]$} \\
\hline & $(\mathrm{VPGVG})_{\mathrm{n}} \mathrm{n}=5-240$ & $\begin{array}{l}\text { IL-10 anti-inflammatory cytokine } \\
\text { and EPO hematopoietic cytokine }\end{array}$ & [17] \\
\hline & $(\mathrm{VPGXG})_{100} \mathrm{X}=\mathrm{V}, \mathrm{G}$, or $\mathrm{A}$ & HIV neutralizing antibody & [41] \\
\hline & $(\mathrm{VPGXG})_{100} \mathrm{X}=\mathrm{V}_{5} \mathrm{G}_{3} \mathrm{~A}_{2}$ & $\begin{array}{l}\mathrm{TNF}^{\mathrm{V}} \mathrm{V}_{\mathrm{H}} \mathrm{H} \text { inhibitor for } \\
\text { prevention of septic shock }\end{array}$ & [18] \\
\hline \multirow[b]{2}{*}{ Targeted peptide ELP fusions } & {$\left[\mathrm{AP} 1-(\mathrm{VGVPG})_{12}\right]_{6}$} & $\begin{array}{l}\text { AP1 peptide for tumor homing to } \\
\text { IL-4 receptor }\end{array}$ & [42] \\
\hline & $(\mathrm{VPGXG})_{120} \mathrm{X}=\mathrm{V}_{1} \mathrm{G}_{7} \mathrm{~A}_{8}$ & $\begin{array}{l}\text { TAT, MTS, and penetratin CPPs } \\
\text { for enhanced cellular uptake and } \\
\text { intracellular delivery of p21 } \\
\text { peptide drug }\end{array}$ & [43] \\
\hline \multirow{3}{*}{$\begin{array}{l}\text { Therapeutic small molecule drug } \\
\text { ELP conjugates }\end{array}$} & $(\mathrm{VPGXG})_{150} \mathrm{X}=\mathrm{V}_{5} \mathrm{~A}_{2} \mathrm{G}_{3}$ and $(\mathrm{VPGXG})_{160} \mathrm{X}=\mathrm{V}_{1} \mathrm{~A}_{8} \mathrm{G}_{7}$ & $\begin{array}{l}\text { Lysine residue for conjugation of } \\
\text { chemotherapeutic doxorubicin } \\
\text { with acid-cleavable hydrazone } \\
\text { linker }\end{array}$ & [44] \\
\hline & $(\mathrm{VPGXG})_{180} \mathrm{X}=\mathrm{V}_{5} \mathrm{~A}_{2} \mathrm{G}_{3}$ & $\begin{array}{l}\text { Cysteine residue for conjugation } \\
\text { of chemotherapeutic doxorubicin } \\
\text { with acid-cleavable hydrazone } \\
\text { linker }\end{array}$ & [45] \\
\hline & $(\mathrm{VPGXG})_{150} \mathrm{X}=\mathrm{V}_{5} \mathrm{~A}_{2} \mathrm{G}_{3}$ and $(\mathrm{VPGXG})_{160} \mathrm{X}=\mathrm{V}_{1} \mathrm{~A}_{8} \mathrm{G}_{7}$ & $\begin{array}{l}\text { Cysteine residue for conjugation } \\
\text { of chemotherapeutic doxorubicin } \\
\text { with enzyme-cleavable peptide } \\
\text { linker and TAT CPP for enhanced } \\
\text { cellular uptake }\end{array}$ & [46] \\
\hline \multirow{3}{*}{ Block copolymer ELP assemblies } & $(\mathrm{VPGXG})_{96}\left[\mathrm{X}=\mathrm{V}_{1} \mathrm{~A}_{8} \mathrm{G}_{7}\right]-(\mathrm{VPGVG})_{60}$ & $\begin{array}{l}\text { RGD and NGR peptide at } \\
\text { hydrophilic terminus for } \\
\text { multivalent display of ligands for } \\
\text { receptors on tumor vasculature }\end{array}$ & [47] \\
\hline & $(\mathrm{VPGXG})_{64}\left[\mathrm{X}=\mathrm{V}_{1} \mathrm{~A}_{8} \mathrm{G}_{7}\right]-(\mathrm{VPGVG})_{90}$ & $\begin{array}{l}\text { NGR peptide at hydrophilic } \\
\text { terminus for multivalent display } \\
\text { of ligand for CD13 receptors on } \\
\text { tumor vasculature }\end{array}$ & [48] \\
\hline & $(\mathrm{VPGSG})_{48}-(\mathrm{VPGIG})_{48}$ & $\begin{array}{l}\text { Knob protein at hydrophilic } \\
\text { terminus for multivalent display } \\
\text { of CAR ligand }\end{array}$ & [49] \\
\hline
\end{tabular}




\begin{tabular}{|c|c|c|c|}
\hline Application & ELP sequence & Pertinent functionalization & Ref \\
\hline & & $\begin{array}{l}\text { FKBP protein at hydrophilic } \\
\text { terminus for rapamycin drug } \\
\text { binding }\end{array}$ & {$[50,51$} \\
\hline \multirow{2}{*}{ Conjugation-driven ELP assemblies } & \multirow{2}{*}{$(\mathrm{VPGXG})_{160} \mathrm{X}=\mathrm{V}_{1} \mathrm{~A}_{8} \mathrm{G}_{7}$} & $\begin{array}{l}\text { (GGC) })_{8} \text { peptide for conjugation } \\
\text { of chemotherapeutic doxorubicin }\end{array}$ & [52] \\
\hline & & $\begin{array}{l}\mathrm{C}(\mathrm{GGC})_{7} \text { peptide for conjugation } \\
\text { of chemotherapeutic paclitaxel }\end{array}$ & [53] \\
\hline ELP polyplexes & $(\mathrm{VPGXG})_{60} \mathrm{X}=\mathrm{V}_{5} \mathrm{~A}_{2} \mathrm{G}_{3}$ & $\begin{array}{l}\mathrm{K}_{8} \text { cationic peptide for ionic } \\
\text { complexation with GFP-encoding } \\
\text { plasmid DNA }\end{array}$ & [54] \\
\hline \multirow{2}{*}{ Coacervate ELP nanoparticles } & $(\mathrm{VPAVG})_{220}$ & $\begin{array}{l}\text { Physical encapsulation of BMP-2 } \\
\text { and BMP-14 cytokines for } \\
\text { promotion of bone growth }\end{array}$ & [55] \\
\hline & {$\left[\mathrm{VG}-(\mathrm{VPGVG})_{4}-\mathrm{VPG}\right]_{8}-\left[\mathrm{VG}-(\mathrm{VPGVG})_{2}-\mathrm{VPGCG}-\mathrm{VPGVG}-\mathrm{VPG}\right]_{2}$} & $\begin{array}{l}\text { KGF protein for promotion of } \\
\text { wound healing }\end{array}$ & {$[56]$} \\
\hline \multirow{3}{*}{ Cross-linked ELP particles } & {$\left[(\mathrm{VPGVG})_{4}-(\mathrm{VPGKG})\right]_{8}-(\mathrm{VPGVG})_{40}$} & $\begin{array}{l}\text { Lysine residues for } \\
\text { glutaraldehyde cross-linking of } \\
\text { solid microparticles with physical } \\
\text { loading of model drugs BSA and } \\
\text { prednisone acetate }\end{array}$ & [57] \\
\hline & {$\left[(\mathrm{VPGVG})_{14}-(\mathrm{VPGKG})\right]_{8}-(\mathrm{VPGVG})_{40}$} & $\begin{array}{l}\text { Lysine residues for } \\
\text { glutaraldehyde cross-linking of } \\
\text { core-shell microparticles with } \\
\text { physical loading of model drugs } \\
\text { rhodamine B, FITC, and } \\
\text { rhodamine-BSA }\end{array}$ & [58] \\
\hline & $\begin{array}{l}\text { EP20-244 (composed of exons from human elastin: 20- } \\
\left.(21-23-24)_{4}\right)\end{array}$ & $\begin{array}{l}\text { Lysine and glutamine residues for } \\
\text { transglutaminase cross-linking of } \\
\text { hollow spheres with physical } \\
\text { loading of plasmid DNA } \\
\text { polyplexes }\end{array}$ & [59] \\
\hline
\end{tabular}


Table 2

Hyperthermia-targeted drug carriers

\begin{tabular}{|c|c|c|c|}
\hline Application & ELP sequence & Pertinent functionalization & Ref \\
\hline \multirow{10}{*}{ Tumor-targeted unimer aggregation } & \multirow{10}{*}{$\begin{array}{l}\text { Temperature-sensitive ELP: }(\mathrm{VPGXG})_{150}{ }^{*} \\
\mathrm{X}=\mathrm{V}_{5} \mathrm{G}_{3} \mathrm{~A}_{2} \text { and Temperature-insensitive } \\
\text { ELP: }(\mathrm{VPGXG})_{160} \mathrm{X}=\mathrm{V}_{1} \mathrm{G}_{7} \mathrm{~A}_{8}\end{array}$} & $\begin{array}{l}\text { Lysine residue for rhodamine } \\
\text { conjugation and visualization of } \\
\text { tumor accumulation in vivo }\end{array}$ & {$[74,75]$} \\
\hline & & $\begin{array}{l}{ }^{14} \mathrm{C} \text { labeling for autoradiography of } \\
\text { tumor accumulation in vivo }\end{array}$ & [26] \\
\hline & & $\begin{array}{l}\text { Lysine residue for Alexa Fluor } 488 / \\
\text { Alexa Fluor } 546 \text { conjugation and } \\
\text { visualization of tumor accumulation } \\
\text { by thermal cycling in vivo }\end{array}$ & [76] \\
\hline & & $\begin{array}{l}\text { Lysine residue for fluorescein } \\
\text { conjugation and quantification of } \\
\text { intracellular uptake in vitro }\end{array}$ & [77] \\
\hline & & $\begin{array}{l}\text { Penetratin CPP for enhanced } \\
\text { intracellular delivery of } \mathrm{H} 1 \text { peptide } \\
\text { drug }\end{array}$ & [79] \\
\hline & & $\begin{array}{l}\text { Bac CPP for enhanced intracellular } \\
\text { delivery of } \mathrm{H} 1(* n=130 \text { for in vitro } \\
\text { applications [80]) or p21 peptide } \\
\text { drug }\end{array}$ & $\begin{array}{l}{[80,81,} \\
85,86]\end{array}$ \\
\hline & & $\begin{array}{l}\text { TAT CPP for enhanced intracellular } \\
\text { delivery of L12 peptide drug }\end{array}$ & [82] \\
\hline & & $\begin{array}{l}\text { SynB1 CPP for enhanced } \\
\text { intracellular delivery of GRG } \\
\text { peptide drug }\end{array}$ & [83] \\
\hline & & $\begin{array}{l}\text { TAT CPP for enhanced intracellular } \\
\text { delivery of doxorubicin conjugated } \\
\text { to cysteine residue with enzyme- } \\
\text { cleavable peptide linker }\end{array}$ & {$[46,87]$} \\
\hline & & $\begin{array}{l}\text { SynB1 CPP for enhanced } \\
\text { intracellular delivery of paclitaxel } \\
\text { or doxorubicin conjugated to } \\
\text { cysteine residue(s) with acid- } \\
\text { cleavable hydrazone linker }\end{array}$ & [88-90] \\
\hline \multirow{4}{*}{ Tumor-targeted unimer-to-micelle transition } & $(\mathrm{VPGXG})_{96}\left[\mathrm{X}=\mathrm{V}_{1} \mathrm{~A}_{8} \mathrm{G}_{7}\right]-(\mathrm{VPGVG})_{60}$ & $\begin{array}{l}\text { NGR at hydrophilic terminus for } \\
\text { temperature-triggered multivalent } \\
\text { targeting of CD13 receptor }\end{array}$ & [47] \\
\hline & $(\mathrm{VPGXG})_{64}\left[\mathrm{X}=\mathrm{V}_{1} \mathrm{~A}_{8} \mathrm{G}_{7}\right]-(\mathrm{VPGVG})_{90}$ & $\begin{array}{l}\text { RGD at hydrophilic terminus for } \\
\text { temperature-triggered multivalent } \\
\text { targeting of } \alpha_{v} \beta_{3} \text { integrin }\end{array}$ & [91] \\
\hline & $(\mathrm{VPGXG})_{96}\left[\mathrm{X}=\mathrm{V}_{1} \mathrm{~A}_{8} \mathrm{G}_{7}\right]-(\mathrm{VPGVG})_{90}$ & $\begin{array}{l}\text { Fn3 at hydrophilic terminus for } \\
\text { temperature-triggered multivalent } \\
\text { targeting of } a_{v} \beta_{3} \text { integrin }\end{array}$ & [92] \\
\hline & $(\mathrm{VPGVG})_{40}-(\mathrm{VPGXG})_{60} \mathrm{X}=\mathrm{A}_{1} \mathrm{G}_{1}$ & $\begin{array}{l}\operatorname{Arg}_{5} \text { or } \operatorname{Arg}_{8} \mathrm{CPP} \text { at hydrophilic } \\
\text { terminus for temperature-triggered } \\
\text { non-specific cellular uptake and } \\
\text { controlled delivery of pro-apoptotic } \\
\text { BH3 peptide drug }\end{array}$ & {$[93,94]$} \\
\hline Tumor-targeted micelle aggregation & $\begin{array}{l}(\mathrm{VPGXG})_{150} \text { or } 160 \mathrm{X}=\mathrm{A}_{\mathrm{a}} \mathrm{V}_{\mathrm{b}} \text { where } \mathrm{a}: \mathrm{b}=1: 0 \\
14: 1,9: 1 \text {, or } 4: 1\end{array}$ & $\begin{array}{l}\mathrm{C}(\mathrm{GGC})_{7} \text { for conjugation of } \\
\text { doxorubicin with acid-cleavable } \\
\text { hydrazone linker }\end{array}$ & [95] \\
\hline
\end{tabular}


Table 3

Therapeutic ELP depots

\begin{tabular}{|c|c|c|c|}
\hline Application & ELP sequence & Functionalization & Ref \\
\hline \multirow{3}{*}{ Depots for cancer } & $(\mathrm{VPGVG})_{120}$ & $\begin{array}{l}\text { Tyrosine residue for conjugation of }{ }^{125} \mathrm{I} \text { or }{ }^{131} \mathrm{I} \\
\text { radionuclides }\end{array}$ & [97] \\
\hline & $(\mathrm{VPGVG})_{60,120, \text { or } 240}$ & $\begin{array}{l}1,4 \text {, or } 7 \text { tyrosine residues for conjugation of }{ }^{125} \text { I or }{ }^{131} \mathrm{I} \\
\text { radionuclides }\end{array}$ & [98] \\
\hline & $\begin{array}{l}(\mathrm{VPGXG})_{160} \text { or } 168 \mathrm{X}=\mathrm{A}_{14} \mathrm{~V}_{1} \mathrm{C}_{1} \text { or } \\
\mathrm{V}_{\mathrm{a}} \mathrm{C}_{\mathrm{b}} \text { where } \mathrm{a}: \mathrm{b}=15: 1,9: 1, \text { or } 5: 1\end{array}$ & $\begin{array}{l}\text { Cysteine residues for disulfide cross-linking and tyrosine } \\
\text { residues for conjugation of }{ }^{125} \text { I radionuclide }\end{array}$ & [99] \\
\hline \multirow{3}{*}{ Depots for joint degeneration } & $(\mathrm{VPGVG})_{47 \mathrm{kDa}}$ & $\begin{array}{l}{ }^{14} \mathrm{C} \text { labeling for visualization of prolonged residence in } \\
\text { rat knee joint }\end{array}$ & {$[100]$} \\
\hline & $\begin{array}{l}(\mathrm{VPGXG})_{90} \mathrm{X}=\mathrm{V}_{5} \mathrm{G}_{3} \mathrm{~A}_{2} \text { and } \\
(\mathrm{VPGVG})_{30}\end{array}$ & IL-1Ra for anti-inflammatory treatment of osteoarthritis & [101] \\
\hline & [(VPGKG)-(VPGVG) $\left.{ }_{16}\right]_{6}$ & $\begin{array}{l}\text { Lysine residues for THPP cross-linking and physical } \\
\text { encapsulation of vancomycin and cefazolin antibiotics }\end{array}$ & [102] \\
\hline \multirow{3}{*}{ Depots for neuroinflammation } & $(\mathrm{VPGVG})_{120}$ & $\begin{array}{l}\text { Tritium radiolabeling for visualization of prolonged } \\
\text { residence in perineural space }\end{array}$ & [103] \\
\hline & $\left(\mathrm{VPGVG}_{60}\right.$ & $\begin{array}{l}\text { sTNFRII for anti-inflammatory treatment of dorsal root } \\
\text { ganglion }\end{array}$ & {$[104,105]$} \\
\hline & $(\mathrm{VPGXG})_{60,80, \text { or } 160} \mathrm{X}=\mathrm{V}_{1} \mathrm{I}_{3} \mathrm{E}_{1}$ & $\begin{array}{l}\text { Glutamate residues for conjugation of curcumin with } \\
\text { degradable carbamate linker }\end{array}$ & [106] \\
\hline \multirow{2}{*}{ Depots for diabetes } & $(\mathrm{VPGVG})_{120}$ & $\begin{array}{l}\text { GLP-1 fusion for release of macromolecular peptide drug } \\
\text { carrier }\end{array}$ & [107] \\
\hline & $(\mathrm{VPGVG})_{240}$ & $\begin{array}{l}\text { (GLP-1 })_{6} \text { fusion via protease cleavable arginine linkers } \\
\text { for release of free peptide drug }\end{array}$ & [108] \\
\hline
\end{tabular}


Table 4

ELP-functionalized hybrid drug delivery systems

\begin{tabular}{|c|c|c|c|}
\hline Application & ELP sequence & Functionalization & Ref \\
\hline \multirow{3}{*}{ ELP-functionalized plasmonic nanoparticles } & $(\mathrm{VPGXG})_{180} \mathrm{X}=\mathrm{V}_{5} \mathrm{G}_{3} \mathrm{~A}_{2}$ & $\begin{array}{l}\text { Lysine residue } \\
\text { (and N-terminal } \\
\text { amine) for } \\
\text { electrostatic } \\
\text { adsorption or } \\
\text { covalent grafting } \\
\text { to MUA- } \\
\text { functionalized } \\
\text { gold nanoparticles }\end{array}$ & {$[109,110]$} \\
\hline & {$\left[\mathrm{VG}-(\mathrm{VPGVG})_{4}-\mathrm{VPG}\right]_{8}-\left[\mathrm{VG}-(\mathrm{VPGVG})_{2} \text {-VPGCG-VPGVG-VPG }\right]_{2}$} & $\begin{array}{l}\text { Cysteine residues } \\
\text { for } \\
\text { functionalization } \\
\text { of gold nanorods } \\
\text { through gold thiol } \\
\text { bonds }\end{array}$ & [111] \\
\hline & {$\left[\mathrm{VG}-(\mathrm{VPGVG})_{4}-\mathrm{VPG}\right]_{8}-\left[\mathrm{VG}-(\mathrm{VPGVG})_{2} \text {-VPGCG-VPGVG-VPG }\right]_{8}$ or 12} & $\begin{array}{l}\text { Cysteine residues } \\
\text { for } \\
\text { functionalization } \\
\text { of gold nanorods } \\
\text { and cross-linking } \\
\text { of composite } \\
\text { matrices with } \\
\text { physical } \\
\text { encapsulation of } \\
\text { 17-AAG drug }\end{array}$ & [112] \\
\hline ELP-functionalized liposomes & $(\mathrm{VPGVG})_{3}$ & $\begin{array}{l}\text { Stearyl group } \\
\text { functionalization } \\
\text { for incorporation } \\
\text { into bilayer of } \\
\text { doxorubicin- } \\
\text { encapsulating } \\
\text { PEGylated } \\
\text { liposomes and } \\
\text { cyclic RGD- } \\
\text { decorated } \\
\text { doxorubicin- } \\
\text { encapsulating } \\
\text { PEGylated } \\
\text { liposomes }\end{array}$ & {$[113,114]$} \\
\hline ELP-functionalized dendrimers & $(\mathrm{VPGVG})_{1}$ & $\begin{array}{l}\text { Boc- } \\
\text { functionalization } \\
\text { for conjugation of } \\
\text { ELP C-terminus } \\
\text { to amines on } \\
\text { PAMAM } \\
\text { dendrimers with } \\
\text { physical } \\
\text { encapsulation of } \\
\text { model drug rose } \\
\text { bengal }\end{array}$ & {$[115]$} \\
\hline
\end{tabular}

